\title{
THERMO-ENVIRONMENTAL ANALYSIS AND MULTI-OBJECTIVE OPTIMIZATION OF PERFORMANCE OF ERICSSON ENGINE IMPLEMENTING AN EVOLUTIONARY ALGORITHM
}

\author{
Mohammad H. Ahmadi1, ${ }^{*}$, Fathollah Pourfayaz ${ }^{2}$, Mohammad Hossein Jahangir ${ }^{2}$
}

\begin{abstract}
This paper makes attempt to optimize a high-temperature differential Ericsson engine with several conditions. A mathematical approach based on the finite-time thermodynamic was proposed with the purpose of gaining thermal efficiency, the output power and the entropy generation rate throughout the Ericsson system with regenerative heat loss, finite rate of heat transfer, finite regeneration process time and conductive thermal bridging loss. In this study, an irreversible Ericsson engine is analyzed thermodynamically in order to optimize its performance. In addition, three Scenarios in multi-objective optimization are presented and the results of them are assessed individually. The first strategy is proposed to maximize the Ecological function, the thermal efficiency and the Exergetic performance criteria. Furthermore, the second strategy is suggested to maximize the Ecological function, the thermal efficiency and Ecological coefficient of performance. The third strategy is proposed to maximize the Ecological function and the thermal efficiency and Dimensionless ecological based thermo-environmental function. Multi-objective evolutionary algorithms based on NSGA-II algorithm was applied to the aforementioned system for calculating the optimum values of decision variables. Decision variables considered in this paper including the regenerator's effectiveness, the high-temperature heat exchanger's effectiveness, the low-temperature heat exchanger's effectiveness, the working fluid temperature in the low-temperature isothermal process and the working fluid temperature in the high-temperature isothermal process. Moreover, Pareto optimal frontier was achieved and an ultimate optimum answer was chosen via three competent decision makers comprising LINMAP, fuzzy Bellman-Zadeh, and TOPSIS approaches. The results from scenarios shown that third scenario is the best scenario.
\end{abstract}

\section{Keywords: Evolutionary Algorithms, Decision-Making, Thermodynamic Analysis, Multi-Objective Optimization, Entropy Generation, Ericsson Engine}

\section{INTRODUCTION}

One of the simplest types of external-combustion engines is the Ericsson engine which employs a compressible fluid as a working fluid. At Carnot efficiency, the Stirling and Ericsson engines can supposedly be an effective engine to convert heat into mechanical work. Little research has been done on the Ericsson engine and more research is related to the Stirling engine.

The material employed for Stirling engine and Ericsson engine construction effects on the thermal boundary for the operation of this engine. In most cases, the engines work with a cooler and heater temperature of 338 and $923 \mathrm{~K}$, correspondingly [1]. The range of efficiency in Stirling engines vary from 30 to $40 \%$ which yielded by normal operating speed varies from 2000 to $4000 \mathrm{rpm}$, and a usual temperature changes from 923 to $1073 \mathrm{~K}[2]$.

Several scholars propose isothermal models like Schmidt's original work (for instance, Urieli and Berchowitz [3], Reader [4] and Hargreaves [5]). Carlson and colleagues [6] improve an ideal approach with nonisothermal heat exchange. These type of approaches propose a development on the isothermal approach as they exclude unfeasibly slow engine speed accompanying with isothermal working spaces and the requirement for infinite heat transfer. Urieli and Kushnir [7] depicted that this analysis can be employed for the purpose of examining the different practical impacts of heat exchangers, non-ideal regenerators, comprising pressure losses and heat transfer. Martaj and colleagues [8] worked on the steady-state operation and illustrated a thermodynamic analysis of a low-temperature Stirling engine, and entropy, energy and exergy balances were reported at each principal component of the engine. The main aims of the Stirling engine inventors can be This paper was recommended for publication in revised form by Regional Editor Alibakhsh Kasaeian

${ }^{1}$ Faculty of Mechanical Engineering, Shahrood University of Technology, Shahrood, Iran

${ }^{2}$ Department of Renewable Energies and Environmental, Faculty of New Sciences and Tech., University of Tehran, Tehran, Iran

*E-mail address: mohammadhosein.ahmadi@gmail.com, mhosein.ahmadi@shahroodut.ac.ir

Orcid id: 0000-0002-0097-2534, 0000-0001-6297-9603, 0000-0002-0991-7646

Manuscript Received 2 August 2017, Accepted 1 October 2017 
categorized into three main groups: maximum power; maximum efficiency; minimum expenses. Markman and colleagues [9] investigated the mechanical-power losses and thermal-flux of a $200 \mathrm{~W}$ beta-configuration of the Stirling engine to improve and intensify the efficiency of engine.

A small Stirling engine with 4 watt output power in $900 \mathrm{rpm}$ rotation speed and $0.1 \mathrm{MPa}$ pressure was investigated and constructed by Kagawa and colleagues [10]. Brandhorst and Chapman [11] established a $5 \mathrm{~kW}$ engine for usage as a power generator in space usages. Ataer [12] used the Lagrangian approach to analyze the regenerators of Stirling cycle engines. Nakajima and colleagues [13] established a $10 \mathrm{~g}$ micro Stirling machine with an approximately $0.05 \mathrm{~cm}^{3}$ piston swept volume. At $10 \mathrm{~Hz}$, the output power of the engine was $10 \mathrm{~mW}$.

Aramtummaphon [14] evaluated an open cycle Stirling engines by employing steam heated from producer gas. The first engine at a maximum speed of $950 \mathrm{rpm}$ produced a specified power of about $1.36 \mathrm{~kW}$, whereas the second engine, amended from the first one, at a maximum speed of $2200 \mathrm{rpm}$ generated a specified power of about $2.92 \mathrm{~kW}$. Takashi Fukui and colleagues [15] invented and built a micro-engine, and its experimental evaluation was implemented; though, the performance of the micro-engine cannot be scaled to the real one. Iwamoto and colleagues [16] compared the efficiency of high temperature and low-temperature Stirling engines with other types of Stirling engines. They investigations depicted that the LTD Stirling efficiency is about $50 \%$ of Carnot efficiency with a similar condition. Wu and colleagues [17] depicted the impacts of regeneration time, heat transfer, and inadequate regeneration on the efficiency of the irreversible Stirling engine cycle. Erbay and Yavuz [18] studied the practical Stirling heat machine for maximum power output circumstances by employing polytropic progressions. They also specified the compression ratio and efficiency at maximum power density and determined the thermal design constraints. Ahmadi and colleagues [19] studied the effects of the Solar Collector Design variables on the Efficiency of Solar Stirling Engine. Ahmadi and colleagues [20-23] proposed a grey-box method to predict the power of Stirling heat engine via machine learning methods.

Investigation of thermodynamic irreversibility in systems acquired significance after the oil crisis in the 1970s to achieve higher efficiencies. The novel approach was entitled as Finite- Time-Thermodynamics (FTT). Primary studies in this field focused on endoreversible power cycle. This engine, named Curzon-AhlbornNovikov (CAN), is reversible internally and irreversible externally [24,25]. Compared with Carnot cycle, which works completely irreversible, Can engine yield more realistic results. Moreover, several studies were conducted on the maximum extractable work from irreversible systems [26-28]. For instance, Angulo-Brown established a standard known as ecological function (ECF) [29]. Yan suggested using ambient temperature ( $\left.T_{0}\right)$ instead of heat sink temperature in Carnot efficiency [30]. Various studies are represented in the literature which has worked on ecological optimization [31-62]. ECOP is another thermo-ecological criterion which is defined and utilized in different thermodynamic cycles [63-72]. A performance coefficient, called exergetic performance criteria (EPC), is another criterion established to find out the relationship between exergy and exergy destruction of a [73-77]. Some studies [78-89] work on obtaining an approach for exergy application in finite time thermodynamic (FTT).

Several studies presented mathematical methods to calculate the overall thermal efficiency of solar powered high-temperature differential dish Stirling engine with regenerator irreversibility and finite heat transfer. Afterwards, the thermal efficiency and absorber working temperature were optimized. [90-92]. Tlili investigated the effects of regenerator effectiveness and internal irreversibility on the thermal efficiency of an endoreversible Stirling heat engine at maximum power condition [93]. Kaushik et al [94-97] studied effects of regeneration and heat transfer of the heat sink and sources on exergy destruction of Stirling and Ericsson engines. Evolutionary algorithms (EA) were originally used throughout the mid-eighties in an effort to unravel the puzzle of this general category [98]. A practical answer to a multi-objective puzzle is to determine a group of answers, each of which fulfills the objectives at a satisfactory degree without being overshadowed by any other answer[99]. Multi-objective optimization issues generally serve a feasibly innumerable group of answers that is to say as Pareto frontier, where examined vectors denote the preeminent probable trade-offs in the objective function area. In this regard, multi-objective optimization of various energy cycles was investigated by numerous nowadays [100-140]. Ahmadi and colleagues [103,105] employed NSGAII to optimize the economic and thermodynamic of a solar-dish Stirling heat engine. They presented another model to evaluate the cooling load of Stirling cryogenic refrigerator cycle as well [113]. Sayyaadi et al. [117] used NSGAII in order to optimize the design elements of a Solar-Driven Heat Engine. Ahmadi and colleagues [121] used MOEA and thermodynamic analysis to optimize an irreversible three-heat-source absorption heat pump. Sadatsakkak et al. [124,125] used thermoeconomic analysis and MOEA to optimize an irreversible regenerative closed Brayton cycle and an endoreversible Braysson cycle. 
In this study, an irreversible Ericsson engine is thermodynamically investigated in order to optimize its performance. In addition, three scenarios are considered in optimization and obtained results are evaluated. The first strategy is proposed to maximize the Ecological function, the thermal efficiency and the Exergetic performance criteria. Furthermore, the second strategy is suggested to maximize the Ecological function, the thermal efficiency and ECOP. The third strategy is proposed to maximize the Ecological function and the thermal efficiency and Dimensionless ecological based thermo-environmental function. MOEAs jointed with NSGA-II approach was executed in this paper. Decision parameters involved in this paper including the regenerator's effectiveness, the high-temperature heat exchanger's effectiveness, the low-temperature heat exchanger's effectiveness, the working fluid temperature in the low-temperature isothermal process and the working fluid temperature in the high-temperature isothermal process. Moreover, Pareto optimal frontier was achieved and an ultimate optimum answer was chosen via three competent decision makers comprising the LINMAP, fuzzy Bellman-Zadeh, and TOPSIS approaches.

\section{SYSTEM DESCRIPTION}

Figure 1 depicts a graphical illustration of an Ericsson heat engine cycle with regenerative heat losses and finite-time heat transfer. As illustrated in Figure 2, ideal Ericsson cycle comprises of 4 progressions containing two isobaric progressions (2-3 and 4-1) in the regenerator and two isothermal (1-2 and 3-4). In a real cycle, it is unfeasible to have an ideal heat transfer in the regenerator, in which the complete amount of absorbed heat (in the process 4-1) is transmitted to the working fluid in the isobaric heating progression (process 2-3). Consequently, a heat transfer loss happens in the regenerator.

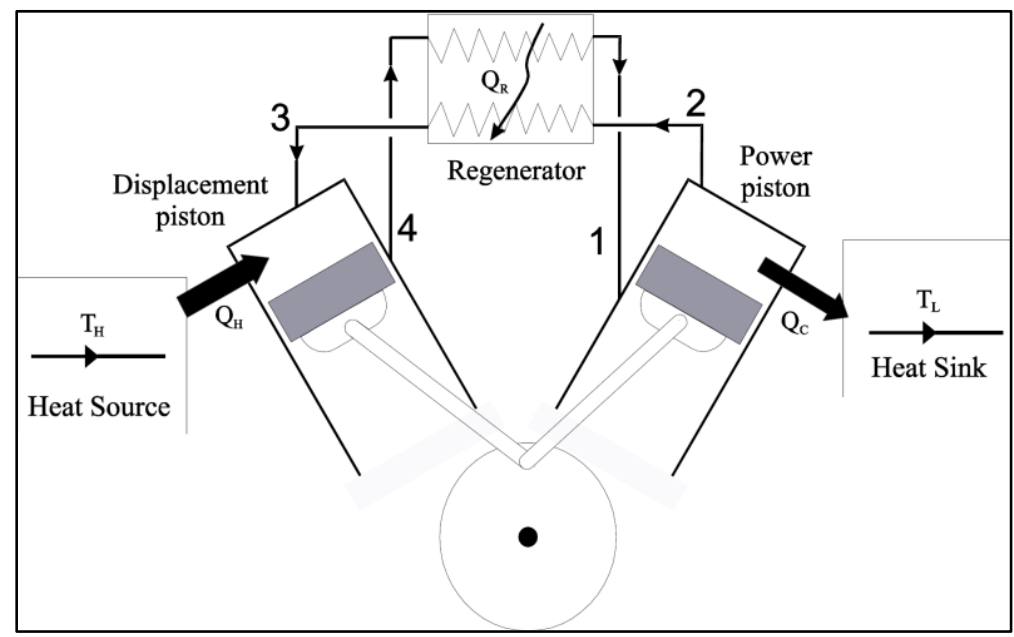

Figure 1. Schematic of proposed Ericsson heat engine

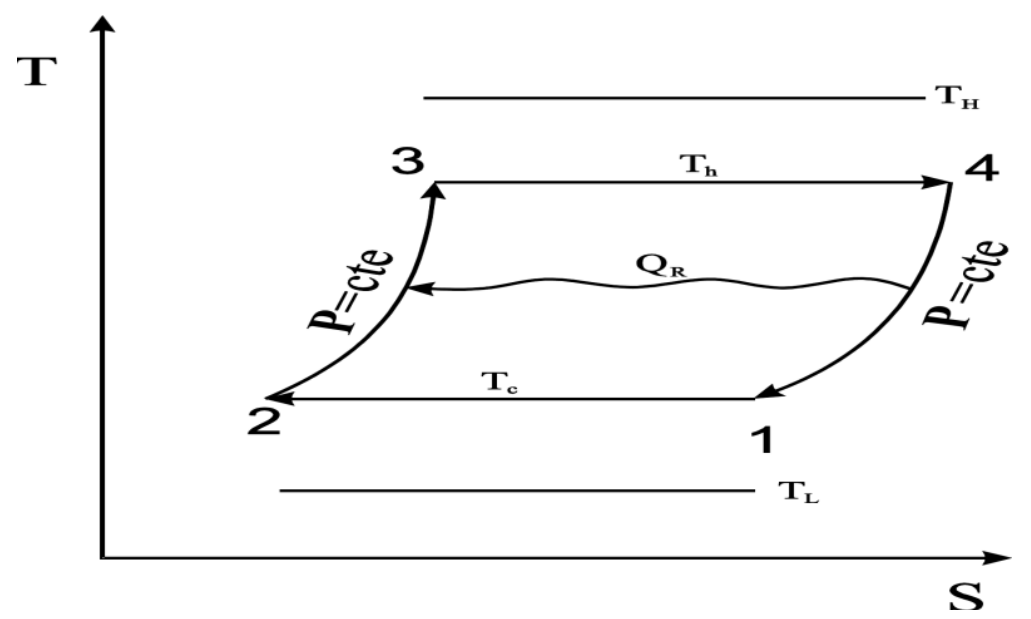

Figure 2. Ericsson engine T-S diagram 


\section{THERMODYNAMIC ANALYSIS OF THE SYSTEM}

It is worth to stress that the finite heat transfer in the regenerative heat transfer $\left(\mathrm{Q}_{\mathrm{r}}\right)$ can be calculated by following expression $[20,91,92]$

$$
\mathrm{Q}_{\mathrm{r}}=\mathrm{nC}_{\mathrm{p}} \varepsilon_{\mathrm{R}}\left(\mathrm{T}_{\mathrm{h}}-\mathrm{T}_{\mathrm{c}}\right)
$$

$\Delta \mathrm{Q}_{\mathrm{r}}$ stands for the heat loss throughout the two regenerative progressions in the cycle and can be determined via the below equation [20,91,92]:

$$
\Delta \mathrm{Q}_{\mathrm{r}}=\mathrm{nC}_{\mathrm{p}}\left(1-\varepsilon_{\mathrm{R}}\right)\left(\mathrm{T}_{\mathrm{h}}-\mathrm{T}_{\mathrm{c}}\right)
$$

$\mathrm{C}_{\mathrm{p}}$ represents the working fluid's specific heat capacity in the regenerative progressions (mole), $\mathrm{n}$ stands for the mass of the working fluid in terms of mole, $\varepsilon_{\mathrm{r}}$ denotes the regenerator's effectiveness, $T_{h}$ and $T_{c}$ stand for the working fluid temperatures in the cold space and hot space, correspondingly.

It is not reasonable to pay no attention to the time of two regeneration progressions when compared with two constant temperature progressions included in the suggested approach. So, via the below equation the regeneration time calculated [94-97]:

$$
\mathrm{t}_{\mathrm{R}}=2 \alpha\left(\mathrm{T}_{\mathrm{h}}-\mathrm{T}_{\mathrm{C}}\right)
$$

The heat absorbed between the heat sink and working fluid $\left(\mathrm{Q}_{\mathrm{L}}\right)$ and the heat released between working fluid and heat source $\left(Q_{H}\right)$, are calculated via the below equations

$$
\begin{aligned}
& \mathrm{Q}_{\mathrm{H}}=\mathrm{nRT}_{\mathrm{h}} \operatorname{Ln} \lambda+\mathrm{nC}_{\mathrm{p}}\left(1-\varepsilon_{\mathrm{R}}\right)\left(\mathrm{T}_{\mathrm{h}}-\mathrm{T}_{\mathrm{c}}\right) \\
& \mathrm{Q}_{\mathrm{L}}=\mathrm{nRT}_{\mathrm{c}} \operatorname{Ln} \lambda+\mathrm{nC}_{\mathrm{p}}\left(1-\varepsilon_{\mathrm{R}}\right)\left(\mathrm{T}_{\mathrm{h}}-\mathrm{T}_{\mathrm{c}}\right)
\end{aligned}
$$

where $\lambda=\frac{p_{1}}{p_{2}}=\frac{p_{4}}{p_{3}}$ is Ratio of pressure throughout the regenerative progressions. Consequently, we have:

$$
\begin{gathered}
\mathrm{Q}_{\mathrm{H}}=\left[\mathrm{C}_{\mathrm{H}} \varepsilon_{\mathrm{H}}\left(\mathrm{T}_{\mathrm{H}}-\mathrm{T}_{\mathrm{h}}\right)+\xi \mathrm{C}_{\mathrm{H}} \varepsilon_{\mathrm{H}}\left(\mathrm{T}_{\mathrm{H}}^{4}-\mathrm{T}_{\mathrm{h}}^{4}\right)\right] \mathrm{t}_{\mathrm{h}} \\
\mathrm{Q}_{\mathrm{L}}=\mathrm{C}_{\mathrm{L}} \varepsilon_{\mathrm{L}}\left(\mathrm{T}_{\mathrm{c}}-\mathrm{T}_{\mathrm{L}}\right) \mathrm{t}_{1}
\end{gathered}
$$

in which $\mathrm{C}_{\mathrm{L}}$ and $\mathrm{C}_{\mathrm{H}}$ denote the external fluids heat capacitance rate in the heat sink and heat source, correspondingly.

$$
\begin{aligned}
& \varepsilon_{\mathrm{H}}=1-\mathrm{e}^{-\mathrm{N}_{\mathrm{H}}} \\
& \varepsilon_{\mathrm{L}}=1-\mathrm{e}^{-\mathrm{N}_{\mathrm{L}}}
\end{aligned}
$$

in which $\varepsilon_{\mathrm{H}}$ and $\varepsilon_{\mathrm{L}}$ stand for the high and low temperature heat exchangers effectiveness, correspondingly and

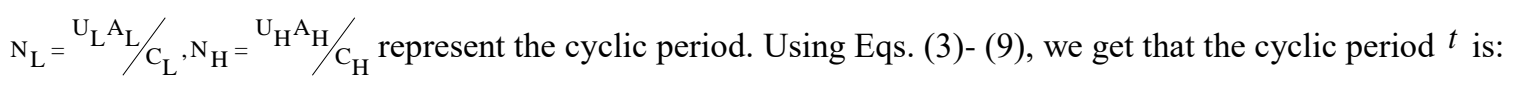




$$
t=\frac{{ }_{n R T} T_{h} L n \lambda+n C_{p}\left(1-\varepsilon_{R}\right)\left(T_{h}-T_{c}\right)}{C_{H} \varepsilon_{H}\left(T_{H}-T_{h}\right)+\xi C_{H} \varepsilon_{H}\left(T_{H}^{4}-T_{h}^{4}\right)}+\frac{n^{2} T_{c} \operatorname{Ln} \lambda+n C_{p}\left(1-\varepsilon_{R}\right)\left(T_{h}-T_{c}\right)}{C_{L}{ }_{L}\left(T_{c}-T_{L}\right)}+2 \alpha\left(T_{h}-T_{c}\right)
$$

Take into account the cyclic period of the Ericsson engine, the thermal efficiency, the output power, and entropy production of the engine can be determined as following as:

$$
\begin{gathered}
P=\frac{W}{t}=\frac{Q_{H}-Q_{L}}{t} \\
\eta_{t}=\frac{Q_{H}-Q_{L}}{Q_{H}} \\
\sigma=\frac{1}{t}\left(\frac{Q_{L}}{T_{L}}-\frac{Q_{H}}{T_{H}}\right)
\end{gathered}
$$

Exergy destruction is the measurement of the irreversibilities or lost work in the system and it is equal to environment temperature $\left(T_{0}, K\right)$ multiply entropy generation rate $(\mathrm{kW} / \mathrm{K})$. The rate of Exergy destruction $(\mathrm{kW})$ is written as following:

$$
\mathrm{E}_{\mathrm{xD}}^{\&}=\mathrm{T}_{0} \sigma
$$

Exergy efficiency:

$$
\varphi=\frac{\mathrm{P}}{\mathrm{P}_{\mathrm{R}}}
$$

Ecological function $(\mathrm{kW})$ can be defined as:

$$
\mathrm{E}=\mathrm{P}-\mathrm{E}_{\mathrm{xD}}^{\mathrm{k}}
$$

The ECOP and exergetic performance criteria are calculated as following as:

$$
\begin{gathered}
\mathrm{ECOP}=\frac{\mathrm{P}}{\mathrm{T}_{0} \sigma} \\
\mathrm{EPC}=\frac{\mathrm{Ex}}{\mathrm{T}_{0} \sigma}
\end{gathered}
$$

Reversible work per unit time of the system (kW) is the difference of exergy input of the system and exergy output from the system and it is described as following:

$$
\mathrm{P}_{\mathrm{R}}=\frac{1}{\mathrm{t}_{\mathrm{cycl}}}\left(\mathrm{Q}_{\mathrm{H}}\left(1-\frac{\mathrm{T}_{0}}{\mathrm{~T}_{\mathrm{H}}}\right)-\mathrm{Q}_{\mathrm{L}}\left(1-\frac{\mathrm{T}_{0}}{\mathrm{~T}_{\mathrm{L}}}\right)\right)
$$


where $\mathrm{m}$ is the total mass, $b_{1}$ is environmental impact of the components $(\mathrm{mPts} / \mathrm{kg}), b_{2}$ is the environmental impact of the fuel (mPts/ MJ), $b_{3}$ is the environmental impact of the lost work ( $\left.\mathrm{mPts} / \mathrm{MJ}\right)$, and $b_{4}(\mathrm{mPts} / \mathrm{MJ})$, is the environmental impact of the mechanical work. Similarly, the ecological based thermo-environmental function is defined as:

$$
\mathrm{B}_{\mathrm{E}}=\frac{\mathrm{E}}{\mathrm{b}_{1} \mathrm{~m}+\mathrm{b}_{2} \mathrm{Q}_{\mathrm{H}}+\mathrm{b}_{3} \mathrm{E}_{\mathrm{xD}}+\mathrm{b}_{4} \mathrm{~W}}
$$

The dimensionless ecological based thermo-environmental function is defined as:

$$
b_{E}=b_{4} B_{E}
$$

Substituting Eqs. (3)- (10) intoEqs. (11) and (12) we have,

$$
\begin{aligned}
& \mathrm{P}=\frac{n \mathrm{nRT}_{\mathrm{h}} \mathrm{Ln} \lambda+\mathrm{nC}_{\mathrm{p}}\left(1-\mathrm{T}_{\mathrm{h}}-\mathrm{T}_{\mathrm{C}}\right) \mathrm{Ln} \lambda}{\mathrm{C}_{\mathrm{H}^{\varepsilon} \mathrm{H}}\left(\mathrm{T}_{\mathrm{h}}-\mathrm{T}_{\mathrm{c}}\right)} \\
& \eta_{t}=\frac{n R\left(T_{h}-T_{C}\right) \operatorname{Ln} \lambda}{{ }_{n R T} \operatorname{Ln} \lambda+n C_{p}\left(1-\varepsilon_{R}\right)\left(T_{h}-T_{c}\right)}
\end{aligned}
$$

\section{MULTI-OBJECTIVE OPTIMIZATION WITH EVOLUTIONARY ALGORITHMS OPTIMIZATION VIA EA}

Genetic Algorithms were firstly proposed by Prof. Holland (1960) by inspiring the concept of natural evolution and Darwinian theorem for optimization purposes [101]. The evolution typically commences from a population of accidentally created individuals and takes place in creations. In each creation, the fitness value of each individual in the population is examined; multiple individuals are stochastically chosen from the present population, and improved to create a fresh population. The fresh population is then employed in the following iteration of the GA. Usually, the GA stops when either an acceptable fitness level was achieved for the population or a maximum number of generations were created. More details of GA can be found in previous works [99, 102].

Also, MOEAs were evolved throughout the past years by frequent examinations on multipart mathematical puzzles and on practical engineering issues and have depicted that they can exclude the complications of conventional approaches [99, 102]. The construction of the MOEA employed in this paper is depicted through Figure 3 [101]. It is worth to highlight that the real values of decision parameters were employed rather than their binary codes.

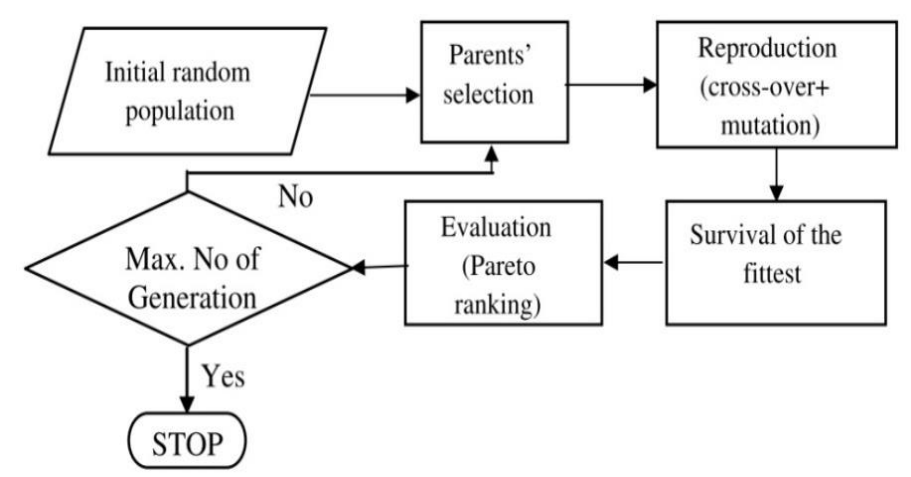

Figure 3. Algorithm steps applied in the study 


\section{NSGA-II APPROACH}

NSGA-II approach was employed in this paper with the purpose of determining the Pareto frontier by running GA. In this regard, NSGA-II organized the answers based on the Pareto theory and arranging nondominated answers into non-dominated layers as illustrated in Figure 4. Put it in another way, if $\mathrm{N}_{\mathrm{p}}$ stands for the population number, it is classified into $\mathrm{N}_{\mathrm{L}}$ layers in which juncture of each two random chosen layers is blank assortment and combination of all layers represents $\mathrm{N}_{\mathrm{p}}$ assortment.

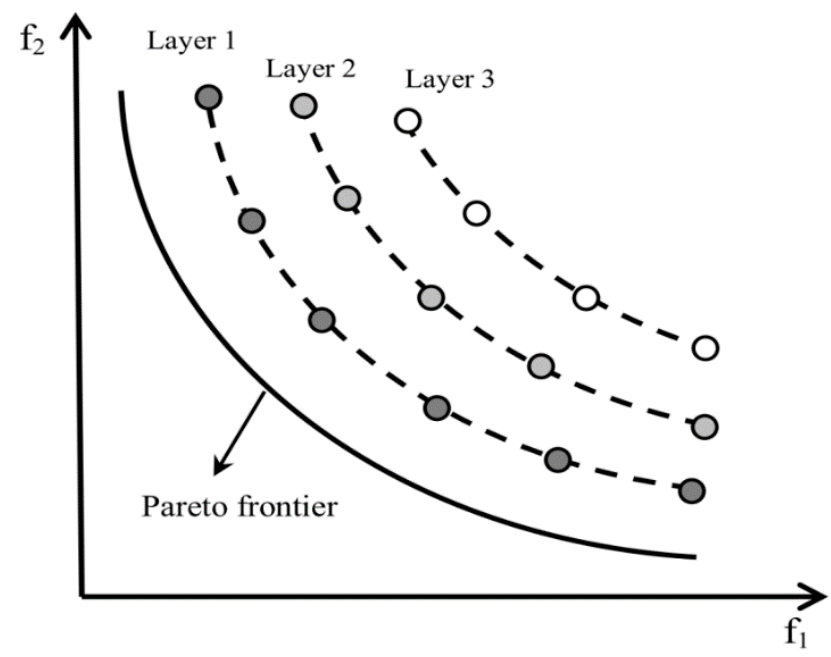

Figure 4. NSGA-II solution layering

The virtual fitness of each answer is equivalent to its layer. Tournament selection was employed for cross over operating in parent choosing between two random chosen layers. So, answer placed on the layer 1, have more opportunity to be chosen for the next creation. Uniform distribution of answers along layers is regulated via an index called "index of crowding distance" for each answer. This criterion is defined as a ratio of detraction of objective functions for two neighbor answers nearby the present answer to the detraction of the minimum and maximum values of that objective. Consequently, for $k_{t h}$ objective of $j_{\text {th }}$ answer, following expression can be used.

$$
i_{d i s, j, k}=\frac{f_{k, j-1}-f_{k, j+1}}{f_{k, \text { max }}-f_{k, \text { min }}}
$$

For margin answers are allocated an infinite distance index. The summation of individual distance values conforming to each objective stands for the overall crowding distance value as follows:

$$
I_{d i s, j}=\sum_{k=1}^{M} i_{d i s, j, k}
$$

in which $\mathrm{j}$ represents the individual index and $\mathrm{M}$ stands for the number of objectives. Figure 5 depicts a graphical illustration of examination of distance index. In this approach, two variables are determined for each answer:

1) Dominant (Layer) number, $\mathrm{N}_{\mathrm{L}}$, namely the number of answers which control the present answer. Description and definitions of domination were described well in Ref. [98, 100]. Dominant number, for nondominated answers of the present population is equal to 0 , consequently, these answers are located in layer 1 . Non-dominated answers for an assortment of the answers not including the layer 1 members are located in layer 2. For $\mathrm{M}$ objectives issue with $\mathrm{N}$ populations, the number of assessments is equal to $\mathrm{MN}^{2}$. This process persisted with the purpose of accommodating all answers in their suitable layers. Furthermore, i rank index for each answer is allocated as its layer number, $\mathrm{N}_{\mathrm{L}}$. 
2) Crowded comparison operator, $\mathrm{n} \prec$, defined as following as:

$$
\begin{aligned}
& \text { A p B if }\left(\operatorname{rank}_{A}<\operatorname{rank}_{B}\right) \\
& \text { Or: } \\
& \left(\left(\operatorname{rank}_{A}=\operatorname{rank}_{B}\right) \text { and } I_{d i s, A}>I_{d i s, B}\right)
\end{aligned}
$$

It reveals that for two answers with dissimilar layers, the answer with the lower layer is desired. Else, for two answers of the same layer, the answer located in the area with a lower concentration of answers is chosen.

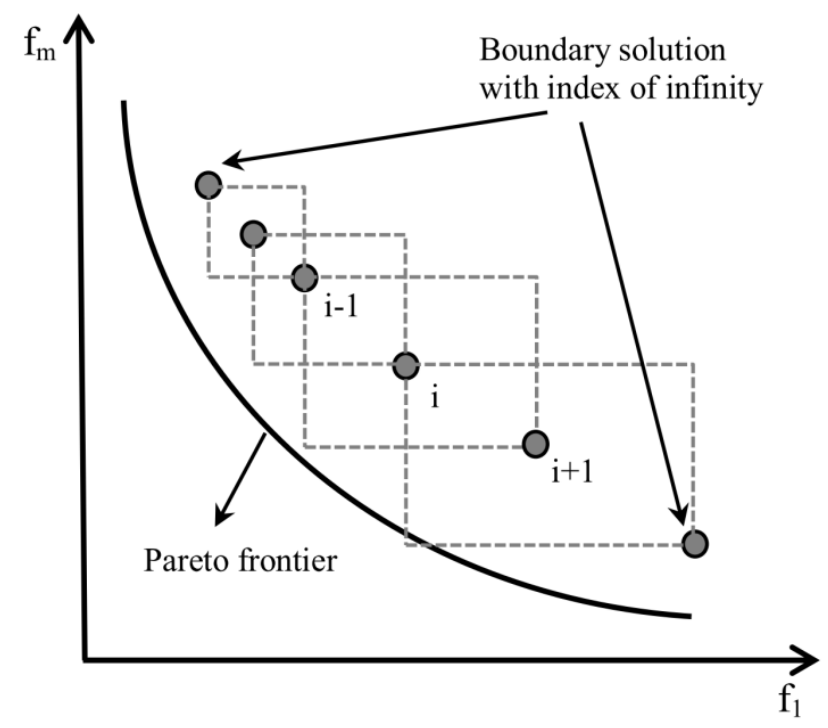

Figure 5. Schematic of distance indexing of individuals in NSGA-II algorithm.Distance indexing of components in NSGA-II algorithms

\section{OBJECTIVE FUNCTION, RESTRAINTS AND DECISION PARAMETERS}

The thermal efficiency, the Ecological function and the Exergetic performance criteria three objective functions for the first scenario, which are evaluated via Eqs. (12 and 16 and 18).

The Ecological function, the thermal efficiency, and ECOP three objective functions for the second scenario, which are evaluated via Eqs. (12 and 16 and 17).

The Ecological function, the thermal efficiency, and Dimensionless ecological based thermoenvironmental function three objective functions for the third scenario, which are evaluated via Eqs. (12 and 16 and 21). Throughout all scenarios proposed in the present paper the below design parameters were employed:

$\varepsilon_{\mathrm{R}}:$ Regenerator's effectiveness

$\varepsilon_{\mathrm{L}}:$ The low-temperature heat exchanger effectiveness

$\varepsilon_{\mathrm{H}}:$ The high-temperature heat exchanger effectiveness

$\mathrm{T}_{\mathrm{h}}$ : The working fluid temperature in the high-temperature isothermal process 3-4

$\mathrm{T}_{\mathrm{c}}$ : The working fluid temperature in the low-temperature isothermal process 1-2

Following limitations were included in the optimization process:

$$
0.7 \leq \varepsilon_{\mathrm{R}} \leq 0.95
$$




$$
\begin{gathered}
0.7 \leq \varepsilon_{\mathrm{H}} \leq 0.9 \\
0.7 \leq \varepsilon_{\mathrm{L}} \leq 0.9 \\
800 \leq \mathrm{T}_{\mathrm{h}} \leq 1100 \mathrm{~K} \\
350 \leq \mathrm{T}_{\mathrm{c}} \leq 500 \mathrm{~K}
\end{gathered}
$$

To determine the optimal design variables of the system, based on genetic algorithm approach a simulation program was coded through Matlab software. Specifications of GA for optimization puzzle are reported in Table 1.

Table 1: Specification of GA for optimization puzzle in this paper

\begin{tabular}{|c|c|}
\hline GA Parameters & Value \\
\hline Population size & 400 \\
\hline Population type & Double vector \\
\hline Tournament size & 2 \\
\hline Selection process & Tournament \\
\hline Maximum number of generations & 1000 \\
\hline Mutation & Restriction dependent \\
\hline
\end{tabular}

Choosing a final optimum answer from Pareto optimal frontier in multi-objective optimization process plays a significant role. In this regard, we should employ decision makers to determine this. Consequently, in this paper three competent decision makers including TOPSIS, Fuzzy and LINMAP were employed as decision makers. Details of these decision makers can be found in previous literature especially references [141, 142].

\section{RESULTS AND DISCUSSION}

\section{Results of First Scenario}

Via running multi-objective optimization approach the thermal efficiency, the Ecological function and the Exergetic performance criteria are maximized concurrently. The objective functions in the applied optimization, and the restrictions that were employed, are formulated by Eqs. (12 and 16 and 18) and Eqs. (2731), respectively.

Design variables in optimization process are the low-temperature heat exchanger's effectiveness, regenerator's effectiveness, the working fluid temperature in the high-temperature isothermal process 3-4, the high-temperature heat exchanger's effectiveness, the working fluid temperature in the low-temperature isothermal process 1-2. Following specifications have been considered for Ericson cycle [91,94]:

$$
\begin{gathered}
n=1, \mathrm{C}_{\mathrm{V}}=15 \mathrm{~J} \cdot \mathrm{mol}^{-1} \cdot \mathrm{K}^{-1}, \mathrm{R}=4.3 \mathrm{~J} \cdot \mathrm{mol}^{-1} \cdot \mathrm{K}^{-1}, \mathrm{~T}_{\mathrm{H}}=1300 \mathrm{~K}, \mathrm{~T}_{\mathrm{L}}=300 \mathrm{~K}, T_{0}=285 \mathrm{~K}, \\
\mathrm{C}_{\mathrm{L}}=\mathrm{C}_{\mathrm{H}}=1000 \mathrm{WK}^{-1}, \mathrm{x}=2^{\prime} 10^{-10}, 1=2, \mathrm{a}=10^{-5} \mathrm{~s} / \mathrm{K} .
\end{gathered}
$$

Pareto optimal frontier for three objective functions, the objective function associated with the thermal efficiency, the Ecological function and the Exergetic performance criteria of the irreversible Ericsson engine are represented in Figure 6.

$$
\begin{gathered}
\mathrm{d}_{+}=\sqrt{\left(\eta_{\mathrm{t}}-\eta_{\mathrm{t}, \mathrm{n}}\right)^{2}+\left(\mathrm{ECF}-\mathrm{ECF}_{\mathrm{n}}\right)^{2}+\left(\mathrm{EPC}-\mathrm{EPC}_{\mathrm{n}}\right)^{2}} \\
\mathrm{~d}_{-}=\sqrt{\left(\eta_{\mathrm{t}}-\eta_{\mathrm{t}, \mathrm{n}, \text { non-ideal }}\right)^{2}+\left(\mathrm{ECF}-\mathrm{ECF}_{\mathrm{n}, \text { non-ideal }}\right)^{2}+\left(\mathrm{EPC}-\mathrm{EPC}_{\mathrm{n}, \text { non-ideal }}\right)^{2}}
\end{gathered}
$$




$$
\mathrm{d}=\frac{\mathrm{d}_{+}}{\left(\mathrm{d}_{+}\right)+\left(\mathrm{d}_{-}\right)}
$$

$\eta_{\mathrm{t}, \mathrm{n}}, \mathrm{ECF}_{\mathrm{n}}$ and $\mathrm{EPC}_{\mathrm{n}}$ denote Euclidian the thermal efficiency, the Ecological function and the Exergetic performance criteria. Furthermore, Table 2 comprises the deviation index $(d)$ for the outcome of each decision maker.

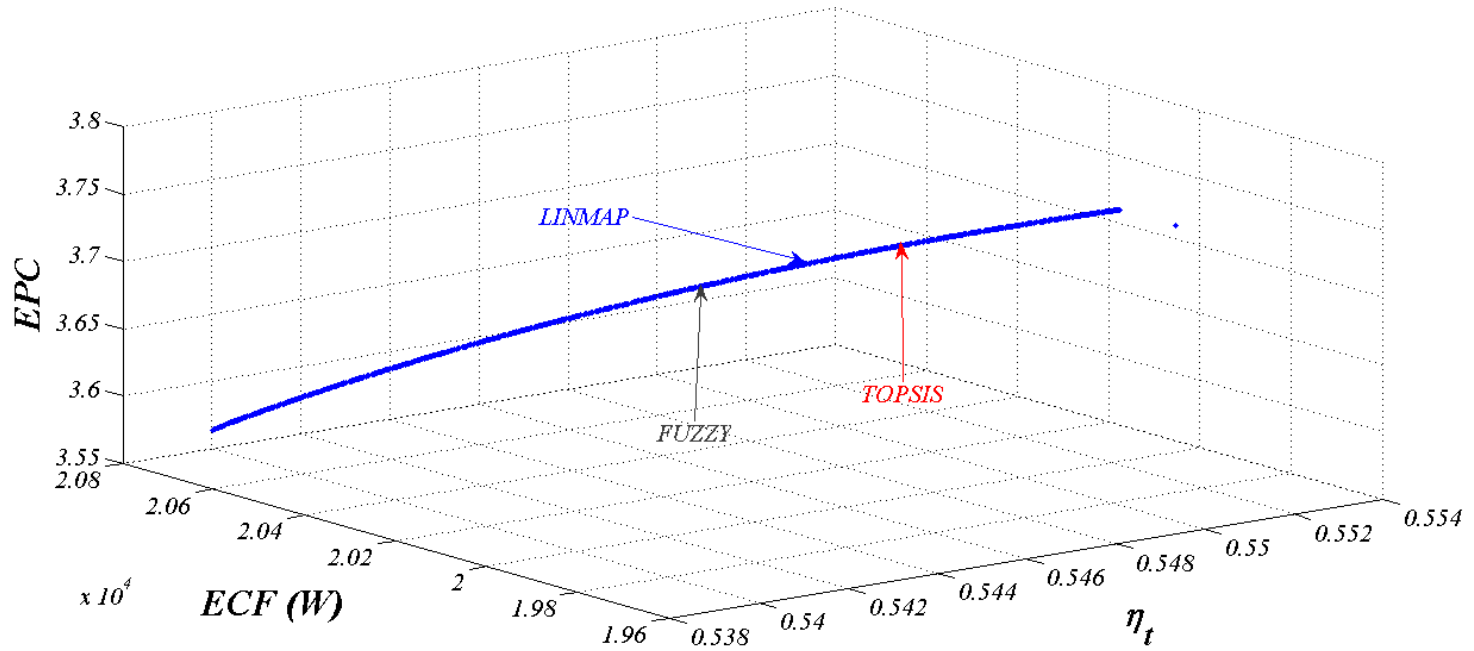

Figure 6. Pareto optimal frontier in the objectives' space of first scenario

Table 2 depicts the optimal outputs achieved for objective functions and decision parameters by executing LINMAP, Fuzzy and TOPSIS approaches for the first scenario. To determine deviations of the results from an ideal and non-ideal solution, following equations were employed.

As reported through Table 2, the deviation indexes for TOPSIS, LINMAP and Fuzzy are 0.036, 0.031 and 0.026, respectively. As clear be seen from this Table, it can conclude that the FUZZY decision-maker has a lower deviation index; consequently the answer which was chosen via the FUZZY decision-maker was selected as a final optimal answer of the multi-objective optimization for the irreversible Ericsson cycle.

Table 2. Outcomes of the decision makers for the first scenario

\begin{tabular}{|c|c|c|c|c|c|c|c|c|c|}
\hline \multirow{2}{*}{$\begin{array}{l}\text { Decision } \\
\text { Making } \\
\text { Method }\end{array}$} & \multicolumn{5}{|c|}{ Decision variables } & \multicolumn{3}{|c|}{ Objectives } & \multirow{2}{*}{$\begin{array}{l}\text { Deviation } \\
\text { index }\end{array}$} \\
\hline & $e_{R}$ & $e_{H}$ & $e_{L}$ & $T_{h}$ & $T_{c}$ & $h_{t}$ & $E C F(W)$ & $E P C$ & \\
\hline TOPSIS & 0.950 & 0.900 & 0.900 & 1094.415 & 364.700 & 0.548 & 20104.500 & 3.721 & 0.036 \\
\hline LINMAP & 0.950 & 0.900 & 0.900 & 1094.390 & 366.479 & 0.547 & 20213.269 & 3.703 & 0.031 \\
\hline Fuzzy & 0.950 & 0.900 & 0.900 & 1094.386 & 368.346 & 0.546 & 20316.560 & 3.684 & 0.026 \\
\hline Ideal point & - & - & - & - & - & 0.554 & 20849.81 & 3.822 & 0 \\
\hline $\begin{array}{c}\text { Non-ideal } \\
\text { point }\end{array}$ & - & - & - & - & - & 0.535 & 19383.34 & 3.504 & $\infty$ \\
\hline
\end{tabular}

To examine the accuracy of the decision maker's analysis of error was performed. Table 3 demonstrates MAPE (Mean Absolute Percentage Error) and MAAE (Maximum Absolute Percentage Error) for results achieved by the decision makers. 
Table 3. Analysis of Error for the results of the first scenario

\begin{tabular}{|c|c|c|c|c|c|c|c|c|c|}
\hline $\begin{array}{c}\text { Decision Making } \\
\text { Method }\end{array}$ & \multicolumn{3}{|c|}{ TOPSIS } & \multicolumn{3}{c|}{ LINMAP } & \multicolumn{3}{c|}{ Fuzzy } \\
\hline Objectives & $h_{t}$ & $E C F$ & $E P C$ & $h_{t}$ & $E C F$ & $E P C$ & $h_{t}$ & $E C F$ & $E P C$ \\
\hline Max Error \% & 2.148 & 8.404 & 3.811 & 1.720 & 7.400 & 3.147 & 0.496 & 4.849 & 1.332 \\
\hline Average Error \% & 1.041 & 4.670 & 1.865 & 0.836 & 4.277 & 1.545 & 0.259 & 2.467 & 0.674 \\
\hline
\end{tabular}

\section{Results of Second Scenario}

Three objective functions are considered for optimization which contain the thermal efficiency, the Ecological function and ECOP (should be maximized) which formulated via Eqs. (12 and 16 and 17), correspondingly.

Objective functions in this scenario are expressed by Eqs. (12 and 16 and 17) and design variables are formulated with Eqs. (27)-(31).

Design variables in optimization process are the same as the first scenario. Following specifications have been considered for Ericson cycle [91,94]:

$$
\begin{gathered}
n=1, \mathrm{C}_{\mathrm{v}}=15 \mathrm{~J} \cdot \mathrm{mol}^{-1} \cdot \mathrm{K}^{-1}, \mathrm{R}=4.3 \mathrm{~J} \cdot \mathrm{mol}^{-1} \cdot \mathrm{K}^{-1}, \mathrm{~T}_{\mathrm{H}}=1300 \mathrm{~K}, \mathrm{~T}_{\mathrm{L}}=300 \mathrm{~K}, T_{0}=285 \mathrm{~K}, \\
\mathrm{C}_{\mathrm{L}}=\mathrm{C}_{\mathrm{H}}=1000 \mathrm{WK}^{-1}, \mathrm{x}=2^{\prime} 10^{-10}, 1=2, \mathrm{a}=10^{-5} \mathrm{~s} / \mathrm{K} .
\end{gathered}
$$

Figure 7 depicts the Pareto frontier in the suggested objectives' space achieved in the optimization scenario. Three ultimate answers were chosen by the LINMAP, Fuzzy Bellman-Zadeh, and TOPSIS decision makers which are highlighted in this figure. According to Figure 7, the obtained points by LINMAP and TOPSIS are approached towards each other. Also, it was shown that the optimal value of the thermal efficiency varied from $53.467 \%$ to $54.844 \%$ and the optimal value of the Ecological function was between $19.972(\mathrm{~kW})$ and $20.850(\mathrm{~kW})$ and the optimal value of the ECOP was between 2.400 and 2.615 .

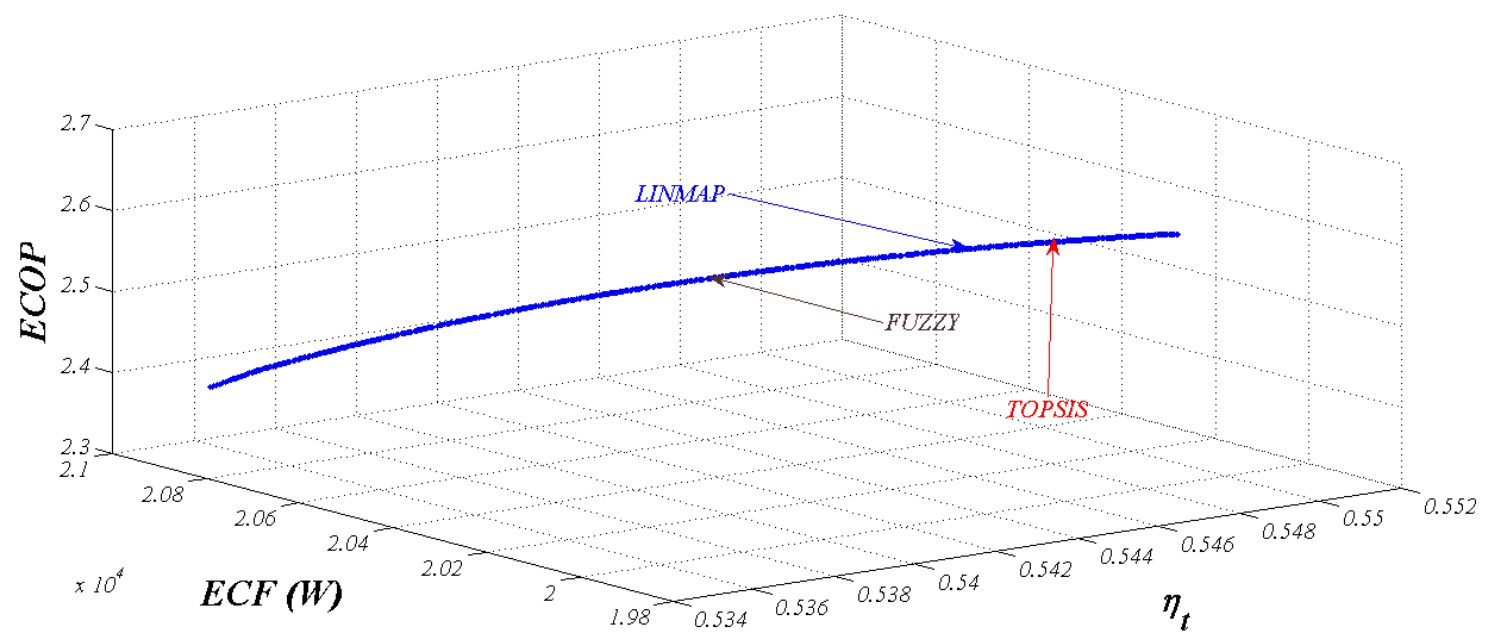

Figure 7. Pareto optimal frontier in the objectives' space of second scenario

Table 4 reports the optimal outputs achieved for objective functions and decision parameters via running TOPSIS, Fuzzy and LINMAP approaches for second scenario. To determine deviations of the results from an ideal and non-ideal solution, following equations were employed.

$$
\mathrm{d}_{+}=\sqrt{\left(\eta_{\mathrm{t}}-\eta_{\mathrm{t}, \mathrm{n}}\right)^{2}+\left(\mathrm{ECF}-\mathrm{ECF}_{\mathrm{n}}\right)^{2}+\left(\mathrm{ECOP}-\mathrm{ECOP}_{\mathrm{n}}\right)^{2}}
$$




$$
\begin{gathered}
\mathrm{d}_{-}=\sqrt{\left(\eta_{\mathrm{t}}-\eta_{\mathrm{t}, \mathrm{n}, \text { non-ideal }}\right)^{2}+\left(\mathrm{ECF}-\mathrm{ECF}_{\mathrm{n}, \text { non-ideal }}\right)^{2}+\left(\mathrm{ECOP}-\mathrm{ECOP}_{\mathrm{n}, \text { non-ideal }}\right)^{2}} \\
d=\frac{d_{+}}{\left(d_{+}\right)+\left(d_{-}\right)}
\end{gathered}
$$

$\eta_{t, n}, \mathrm{ECF}_{\mathrm{n}}$ and $\mathrm{ECOP}_{\mathrm{n}}$ denote Euclidian the thermal efficiency, the Ecological function and the ECOP. Furthermore, Table 4 comprises the deviation index $(d)$ for the outcome of each decision maker.

As reported in Table 4, the deviation indexes for TOPSIS, LINMAP and Fuzzy are 0.035, 0.030 and 0.017 , respectively. As clear be seen from this Table, it can conclude that the FUZZY decision-maker has a lower deviation index; consequently the answer which was chosen via the FUZZY decision-maker was selected as a final optimal answer of the multi-objective optimization for the irreversible Ericsson cycle.

\begin{tabular}{|c|c|c|c|c|c|c|c|c|c|}
\hline \multirow[b]{2}{*}{$\begin{array}{c}\text { Decision Making } \\
\text { Method }\end{array}$} & \multicolumn{5}{|c|}{ Decision variables } & \multicolumn{3}{|c|}{ Objectives } & \multirow[b]{2}{*}{$\begin{array}{c}\text { Deviation } \\
\text { index }\end{array}$} \\
\hline & $e_{R}$ & $e_{H}$ & $e_{L}$ & $T_{h}$ & $T_{c}$ & $h_{t}$ & $E C F(W)$ & ECOP & \\
\hline TOPSIS & 0.950 & 0.900 & 0.900 & 1088.063 & 364.556 & 0.547 & 20120.226 & 2.594 & 0.035 \\
\hline LINMAP & 0.950 & 0.900 & 0.900 & 1088.062 & 366.269 & 0.546 & 20226.707 & 2.576 & 0.030 \\
\hline Fuzzy & 0.950 & 0.900 & 0.900 & 1088.039 & 371.284 & 0.543 & 20487.154 & 2.526 & 0.017 \\
\hline Ideal point & - & - & - & - & - & 0.554 & 20849.810 & 2.713 & 0 \\
\hline Non-ideal point & - & - & - & - & - & 0.535 & 19383.340 & 2.399 & $\infty$ \\
\hline
\end{tabular}

Table 4. Outcomes of the decision makers for the second scenario

Finally, deviations of the final answers gained by each decision maker and ideal answer are assessed. Table 5 demonstrates MAPE and MAAE of results obtained via the aforesaid decision makers.

Table 5. Analysis of error for the results of the second scenario

\begin{tabular}{|c|c|c|c|c|c|c|c|c|c|}
\hline Decision Making Method & \multicolumn{3}{|c|}{ TOPSIS } & \multicolumn{3}{c|}{ LINMAP } & \multicolumn{3}{c|}{ Fuzzy } \\
\hline Objectives & $h_{t}$ & $E C F$ & $E C O P$ & $h_{t}$ & $E C F$ & $E C O P$ & $h_{t}$ & $E C F$ & $E C O P$ \\
\hline Max Error \% & 2.148 & 8.404 & 3.811 & 1.720 & 7.400 & 3.147 & 0.496 & 4.849 & 1.332 \\
\hline Average Error \% & 1.041 & 4.670 & 1.865 & 0.836 & 4.277 & 1.545 & 0.259 & 2.467 & 0.674 \\
\hline
\end{tabular}

\section{Results of Third Scenario}

Throughout this scenario we attempted to maximize the thermal efficiency, the Ecological function and Dimensionless ecological based thermo-environmental function at the same time. The objective functions, and the limitations which were employed, are expressed by Eqs. (12 and 16 and 21) and Eqs. (27-31), respectively. Design variables in optimization process are the same as the first scenario. Following specifications have been considered for Ericson cycle [91, 94]:

$$
\begin{aligned}
n=1, \mathrm{C}_{\mathrm{V}} & =15 \mathrm{~J} \mathrm{~mol}^{-1} \cdot \mathrm{K}^{-1}, \mathrm{R}=4.3 \mathrm{~J} \cdot \mathrm{mol}^{-1} \cdot \mathrm{K}^{-1}, \mathrm{~T}_{\mathrm{H}}=1300 \mathrm{~K}, \mathrm{~T}_{\mathrm{L}}=300 \mathrm{~K}, T_{0}=285 \mathrm{~K}, \\
\mathrm{C}_{\mathrm{L}} & =\mathrm{C}_{\mathrm{H}}=1000 \mathrm{WK}^{-1}, \mathrm{x}=2^{\prime} 10^{-10}, 1=2, \mathrm{a}=10^{-5} \mathrm{~s} / \mathrm{K} .
\end{aligned}
$$

Pareto optimal frontier for three objective functions, the objective function associated with the Ecological function, the thermal efficiency, and Dimensionless ecological based thermo-environmental function of the irreversible Ericsson engine are represented in Figure 8. 


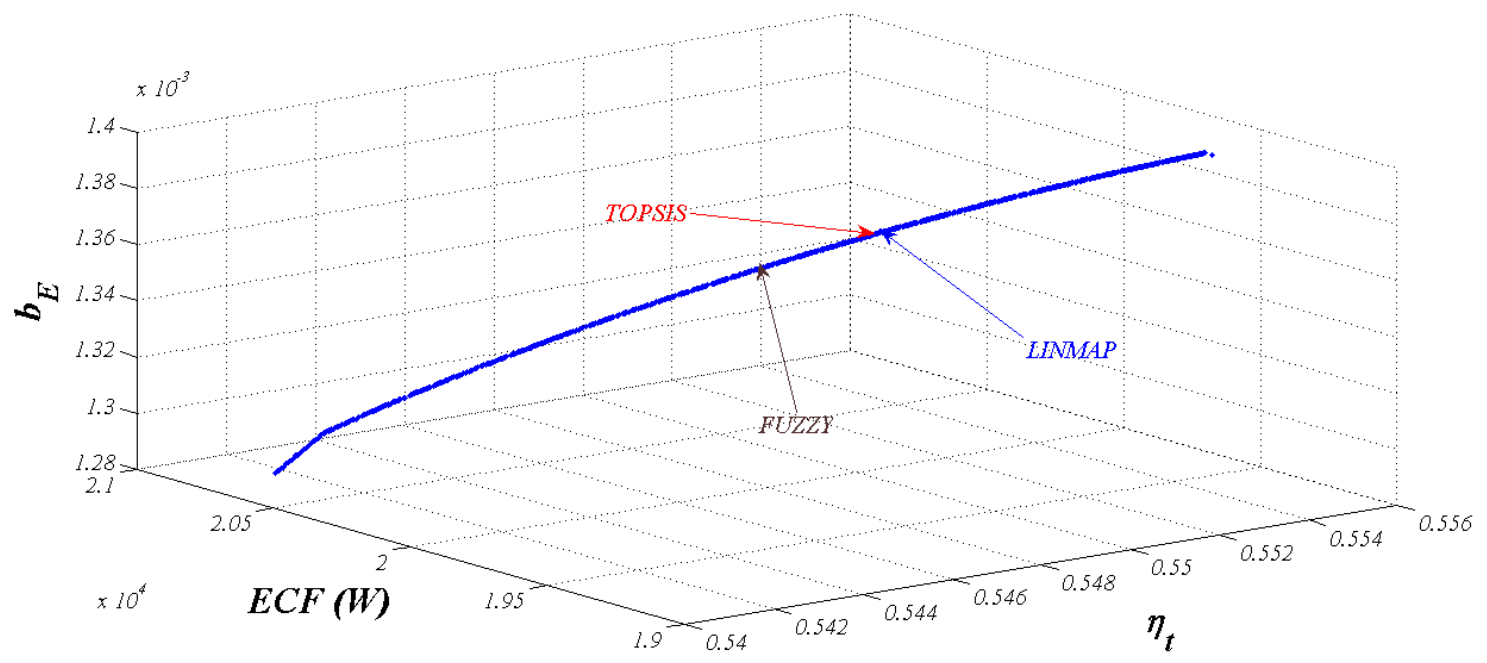

Figure 8. Pareto optimal frontier in the objectives' space of third scenario

Table 6 reports the optimal outputs achieved for objective functions and decision parameters via running TOPSIS, Fuzzy and LINMAP approaches for third scenario. To determine deviations of the results from an ideal and non-ideal solution, following equations were employed.

$$
\begin{aligned}
& d_{+}=\sqrt{\left(\eta_{t}-\eta_{t, n}\right)^{2}+\left(E C F-E C F_{n}\right)^{2}+\left(b_{E}-b_{E, n}\right)^{2}} \\
& d_{-}=\sqrt{\left(\eta_{t}-\eta_{t, n, \text { non-ideal }}\right)^{2}+\left(E C F-E C F_{n, \text { non-ideal }}\right)^{2}+\left(b_{E}-b_{E, n, \text { non-ideal }}\right)^{2}} \\
& d=\frac{d_{+}}{\left(d_{+}\right)+\left(d_{-}\right)}
\end{aligned}
$$

$\eta_{\mathrm{t}, \mathrm{n}}, \mathrm{ECF}_{\mathrm{n}}$ and $\mathrm{b}_{\mathrm{E}, \mathrm{n}}$ denote Euclidian the thermal efficiency, the Ecological function and the Dimensionless ecological based thermo-environmental function. Furthermore, Table 6 comprises the deviation index $(d)$ for the outcome of each decision maker.

As reported through Table 6, the deviation indexes for TOPSIS, LINMAP and Fuzzy are 0.052, 0.043 and 0.035 , respectively. As clear be seen from this Table, it can conclude that the FUZZY decision-maker has a lower deviation index; consequently the answer which was chosen via the FUZZY decision-maker was selected as a final optimal answer of the multi-objective optimization for the irreversible Ericsson cycle.

Table 6. Outcomes of the decision makers for the third scenario

\begin{tabular}{|c|c|c|c|c|c|c|c|c|c|}
\hline \multirow{2}{*}{$\begin{array}{c}\text { Decision } \\
\text { Making } \\
\text { Method }\end{array}$} & \multicolumn{5}{|c|}{ Decision variables } & \multicolumn{3}{|c|}{ Objectives } & \multirow{2}{*}{$\begin{array}{c}\text { Deviation } \\
\text { index }\end{array}$} \\
\cline { 2 - 10 } & $e_{R}$ & $e_{H}$ & $e_{L}$ & $T_{h}$ & $T_{c}$ & $h_{t}$ & $E C F(W)$ & $b_{E}{ }^{\prime} 10^{3}$ & \\
\hline TOPSIS & 0.950 & 0.900 & 0.900 & 1096.679 & 360.197 & 0.552 & 19772.681 & 1.378 & 0.052 \\
\hline LINMAP & 0.950 & 0.900 & 0.900 & 1096.679 & 362.556 & 0.550 & 19948.829 & 1.366 & 0.043 \\
\hline Fuzzy & 0.950 & 0.900 & 0.900 & 1096.668 & 365.063 & 0.549 & 20115.565 & 1.353 & 0.035 \\
\hline Ideal point & - & - & - & - & - & 0.554 & 20849.810 & 1.400 & 0 \\
\hline Non-ideal point & - & - & - & - & - & 0.535 & 19383.340 & 1.200 & $\infty$ \\
\hline
\end{tabular}


Finally, deviations of the final answers gained by each decision maker and ideal answer are assessed. Table 7 explicates MAAE and MAPE of results obtained via the aforesaid decision makers.

Table 7. Analysis of error analysis for the results of the third scenario

\begin{tabular}{|c|c|c|c|c|c|c|c|c|c|}
\hline $\begin{array}{c}\text { Decision } \\
\text { Making } \\
\text { Method }\end{array}$ & \multicolumn{3}{|c|}{ TOPSIS } & \multicolumn{3}{c|}{ LINMAP } & \multicolumn{3}{c|}{ Fuzzy } \\
\hline Objectives & $h_{t}$ & $E C F$ & $b_{E}$ & $h_{t}$ & $E C F$ & $b_{E}$ & $h_{t}$ & $E C F$ & $b_{E}$ \\
\hline Max Error \% & 2.148 & 8.404 & 3.811 & 1.720 & 7.400 & 3.147 & 0.496 & 4.849 & 1.332 \\
\hline $\begin{array}{c}\text { Average Error } \\
\%\end{array}$ & 1.041 & 4.670 & 1.865 & 0.836 & 4.277 & 1.545 & 0.259 & 2.467 & 0.674 \\
\hline
\end{tabular}

Figure 9 depicts the comparison between thermal efficiency gained from three scenarios. As clear be seen from Figure 9, the third scenario has the highest value of thermal efficiency compared to other scenarios. Moreover, the lowest value of thermal efficiency is for the second scenario. It should be noted that thermal efficiency was an objective function for all the scenarios.

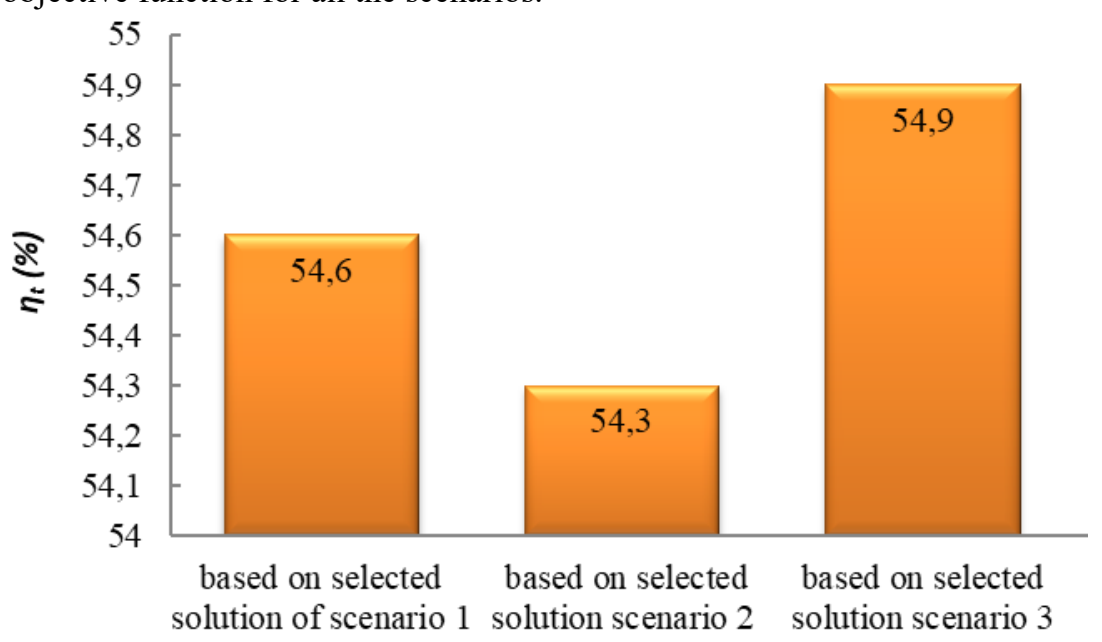

Figure 9. Comparison of thermal efficiency between different optimization scenarios

Figure 10 depicts the comparison between ECF gained from three scenarios. As clear be seen from Figure 10 , the second scenario has the highest value of ECF compared to other scenarios. Moreover, the lowest value of ECF is for the third scenario. It should be noted that ECF was an objective function for all the scenarios.

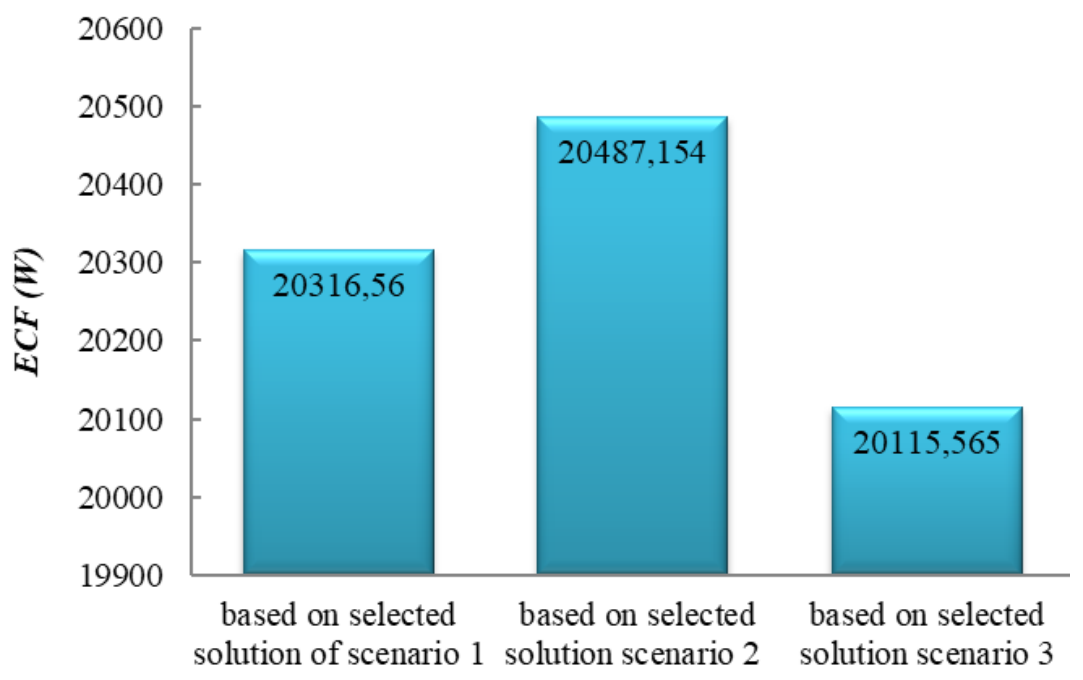

Figure 10. Comparison of ECF between different optimization scenarios 
Figure 11 depicts the comparison between EPC gained from three scenarios. As clear be seen from Figure 11, the third scenario has the highest value of EPC compared to other scenarios. Moreover, the lowest value of EPC is for the second scenario. It should be noted that EPC was an objective function just for the first scenario and the values of EPC in other scenarios were calculated at optimum conditions gained from optimization process.

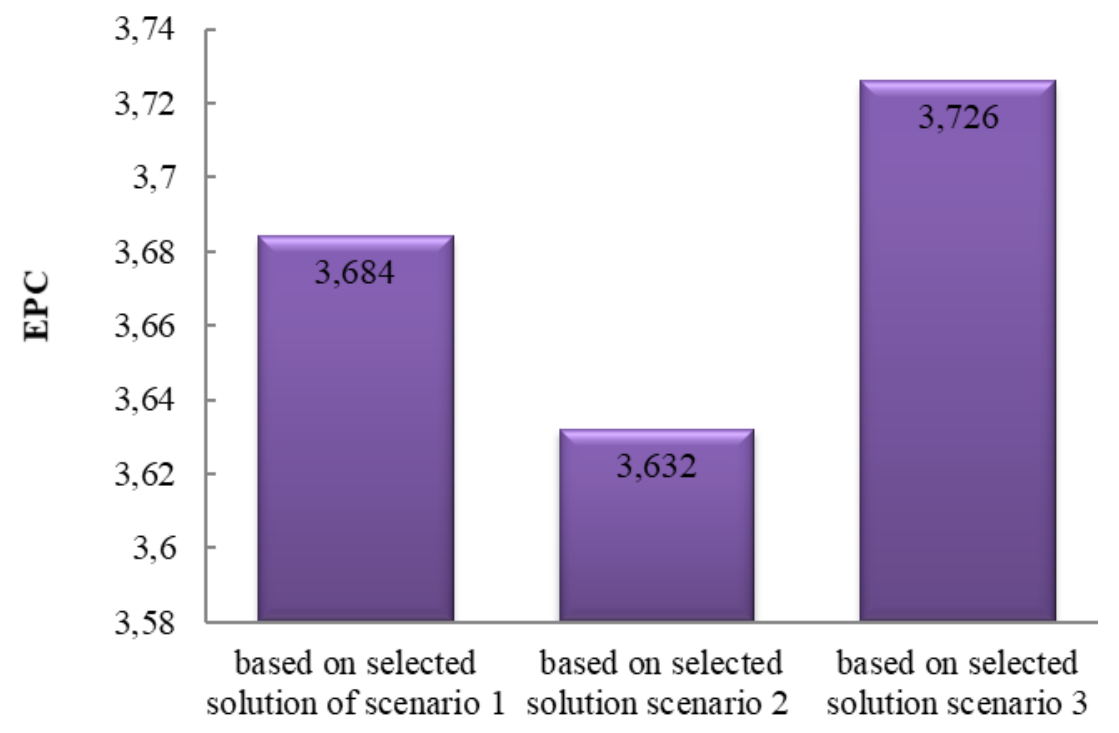

Figure 11. Comparison of EPC between different optimization scenarios

Figure 12 depicts the comparison between ECOP gained from three scenarios. As clear be seen from Figure 12, the third scenario has the highest value of ECOP compared to other scenarios. Moreover, the lowest value of ECOP is for the second scenario. It should be noted that ECOP was an objective function just for the second scenario and the values of ECOP in other scenarios were calculated at optimum conditions gained from optimization process.

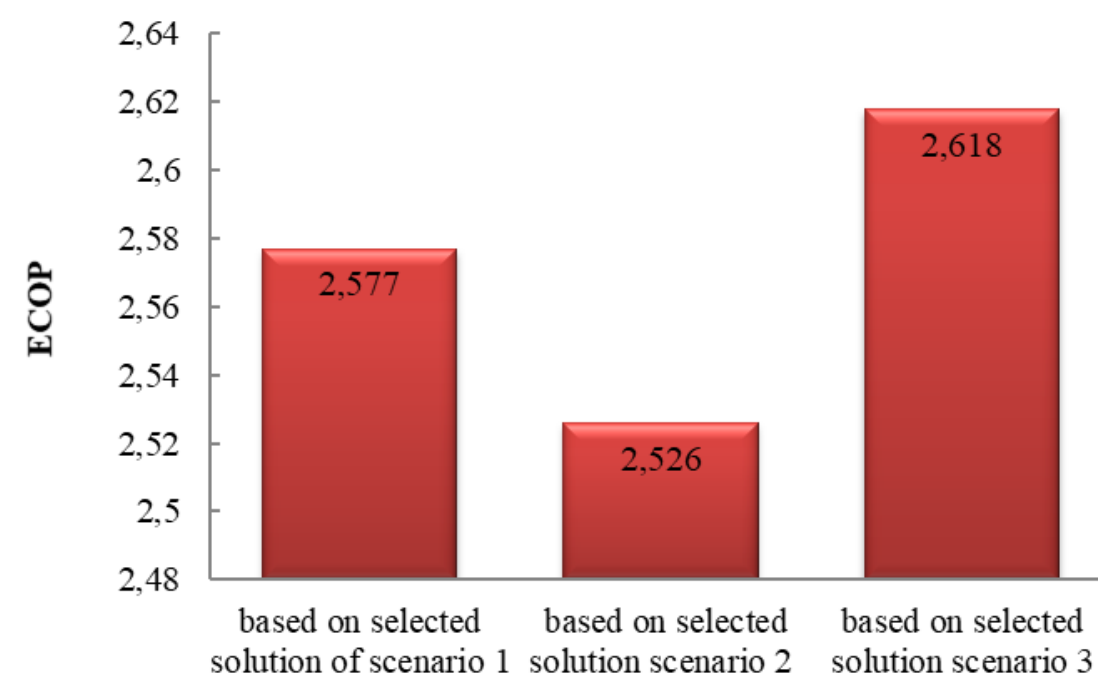

Figure 12. Comparison of ECOP between different optimization scenarios

Figure 13 depicts the comparison between Dimensionless ecological based thermo-environmental function gained from three scenarios. As clear be seen from Figure 13, the third scenario has the highest value of Dimensionless ecological based thermo-environmental function compared to other scenarios. Moreover, the lowest value of dimensionless ecological based thermo-environmental function is for the second scenario. It should be noted that dimensionless ecological based thermo-environmental function was an objective function 
just for the third scenario and the values of dimensionless ecological based thermo-environmental function in other scenarios were calculated at optimum conditions gained from optimization process.

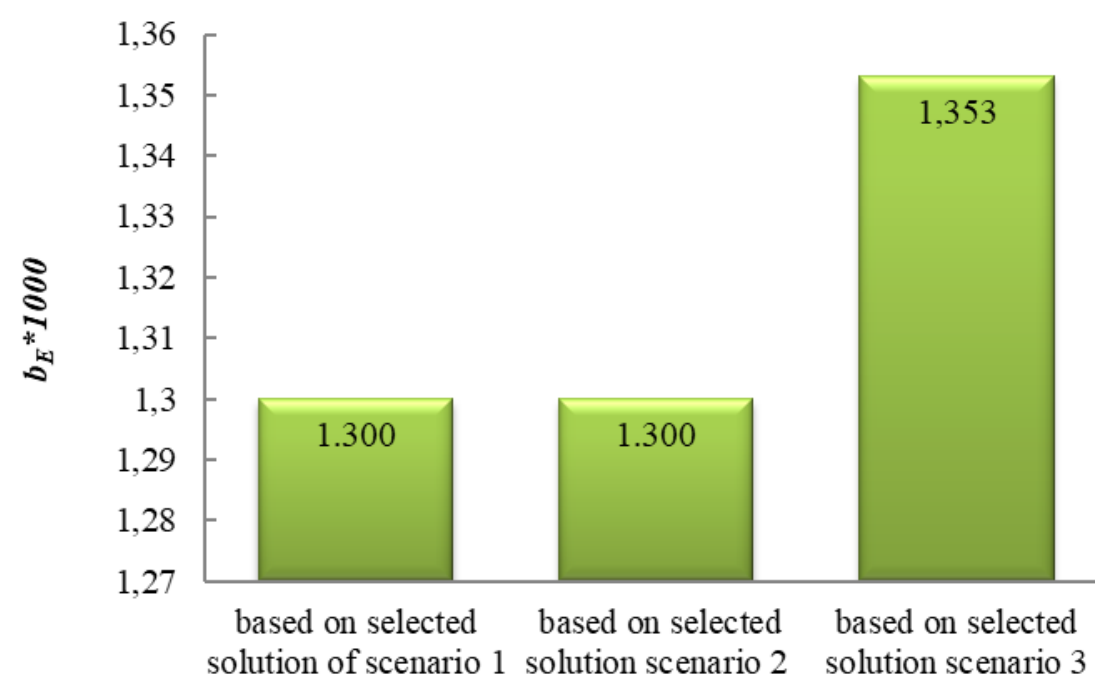

Figure13. Comparison of dimensionless ecological based thermo-environmental function between different optimization scenarios

Finally, as it is clearly seen from Figures 9 through 13, it can conclude that the third scenario was the best scenario in comparison other proposed scenarios. This is main due to the condition when $b_{E}$ is maximum the values of ECOP, EPC and thermal efficiency are maximum. In other words, maximizing $b_{E}$ results in gaining maximum values of ECOP, EPC and thermal efficiency.

\section{CONCLUSIONS}

This paper made attempt to illustrate multi-objective optimization of Ericson system based on finitetime thermodynamics analysis. In this regard, the optimum values of the Ecological function, the thermal efficiency, Exergetic performance criteria, the ECOP, and dimensionless ecological based thermo-environmental function of the Ericsson engine have been determined. The thermal efficiency, output power, and entropy generation rate throughout the engine have been chosen as parallel objective functions in the optimization process. Furthermore, the low temperature heat exchanger's effectiveness $\left(\varepsilon_{\mathrm{L}}\right)$,the regenerator's effectiveness ( $\left.\varepsilon_{R}\right)$, the working fluid temperature in the high temperature isothermal process $\left(T_{h}\right)$, the high temperature heat exchanger's effectiveness $\left(\varepsilon_{\mathrm{H}}\right)$, and working fluid temperature in the low temperature isothermal process $\left(\mathrm{T}_{\mathrm{c}}\right)$ have been chosen as design variables with definite limitations in optimization process. MOEA based on NSGAII approach was applied to the aforementioned system for calculating the optimum values of decision variables. Moreover, Pareto optimal frontier was achieved and an ultimate optimum answer was chosen via three competent decision makers comprising the LINMAP, fuzzy Bellman-Zadeh, and TOPSIS approaches. If the main goal is ECF, the results of the second scenario are the best. Also, If the main goals are thermal efficiency, ECOP, EPC and Dimensionless ecological based thermo-environmental function the results of the third scenario are the best.

\section{NOMECLATURE}

A

$\mathrm{C}$

$\mathrm{C}_{\mathrm{p}}$

$\mathrm{h}$

n

$\mathrm{N}$

$\mathrm{P}$
Area, $\left[\mathrm{m}^{2}\right]$

Heat capacitance rate,[W/K]

Specific heat capacity, $\left[\mathrm{Jmol}^{-1} \mathrm{~K}^{-1}\right]$

heat transfer coefficient $\left[\mathrm{Wm}^{-2} \mathrm{~K}^{-1}\right]$

Number of mole[-]

Number of heat transfer units[-],

Power output ,[W] 


\begin{tabular}{ll}
$\mathrm{Q}$ & Heat, $[\mathrm{J}]$ \\
$\mathrm{R}$ & The gas constant, $\left[\mathrm{Jmol}^{-1} \mathrm{~K}^{-1}\right]$ \\
$\mathrm{S}$ & Entropy, $[\mathrm{J} / \mathrm{K}]$ \\
$\mathrm{T}$ & Temperature, $[\mathrm{K}]$ \\
$\mathrm{t}$ & Time,$[\mathrm{s}]$ \\
$\mathrm{P}$ & Power, $[\mathrm{W}]$ \\
$\mathrm{p}$ & Pressure of the working fluid \\
$\mathrm{W}$ & Output work, $[\mathrm{J}]$ \\
0 & ambient \\
$l$ & Inlet \\
$1,2,3,4$ & State points \\
2 & Outlet \\
$c$ & Cold side \\
$d i s$ & distance \\
$H$ & Heat source \\
$h$ & Hot side \\
$L$ & Cold side/Heat sink \\
$R$ & Regenerator \\
$r e c$ & absorber \\
$\eta$ & Thermal efficiency[-] \\
$\varepsilon$ & Effectiveness and emissivity factor[-] \\
$\lambda$ & Ratio of pressure during the regenerative processes $[-]$ \\
$\delta$ & Stefan's constant $\left[\mathrm{Wm} \mathrm{K}^{-2}\right]$ \\
$\sigma$ & Entropy production $[\mathrm{W} / \mathrm{K}]$ \\
& \\
\hline &
\end{tabular}

\section{REFERENCES}

[1] Tlili, I., and Sa'ed, A. (2013). Thermodynamic evaluation of a second order simulation for Yoke Ross Stirling engine. Energy conversion and management, 68, 149-160.

[2] Formosa, F., and Despesse, G. (2010). Analytical model for Stirling cycle machine design. Energy Conversion and Management, 51(10), 1855-1863.

[3] Berchowitz, D. M., and Urieli, I. (1984). Stirling cycle engine analysis. Adam Hilger Ltd, Bristol.

[4] Reader, G. T. (1983). Hooper C. Stirling engines. London and New York: EandFN Spon.

[5] Hargreaves, C. M. (1991). The Phillips stirling engine.

[6] Carlson, H., Commisso, M. B., and Lorentzen, B. (1990, August). Maximum obtainable efficiency for engines and refrigerators based on the Stirling cycle. In Proceedings of the 25th Intersociety Energy Conversion Engineering Conference (Vol. 5, pp. 366-371). IEEE.

[7] Urieli, I., and Kushnir, M. (1982). The ideal adiabatic cycle-A rational basis for Stirling engine analysis. In IECEC'82; Proceedings of the Seventeenth Intersociety Energy Conversion Engineering Conference (pp. 1662-1668).

[8] Martaj, N., Grosu, L., and Rochelle, P. (2007). Thermodynamic study of a low temperature difference Stirling engine at steady state operation. International Journal of Thermodynamics, 10(4), 165.

[9] Markman, M. A., SHMATOK, I., and KRASOVSKII, V. (1983). An experimental investigation of a lowpower Stirling engine. Geliotekhnika, (3), 19-24.

[10] Kagawa, N., Araoka, K., Sakuma, T., and Ichikawa, S. (1990, August). Design and development of a miniature Stirling engine. In Proceedings of the 25th Intersociety Energy Conversion Engineering Conference (Vol. 5, pp. 442-447). IEEE.

[11] Brandhorst Jr, H. W., and Chapman Jr, P. A. (2008). New $5 \mathrm{~kW}$ free-piston Stirling space convertor developments. Acta Astronautica, 63(1-4), 342-347.

[12] Ataer, Ö. E. (2002). Numerical analysis of regenerators of free-piston type Stirling engines using Lagrangian formulation. International journal of refrigeration, 25(5), 640-652.

[13] Nakajima, N., Ogawa, K., and Fujimasa, I. (1989). Study on microengines: miniaturing Stirling engines for actuators. Sensors and Actuators, 20(1-2), 75-82. 
[14] Aramtummaphon, D. (1996). A study of the feasibility of using heat energy from producer gas for running Stirling engine by steam as working Fluid (Doctoral dissertation, Master thesis, King Mongkut's University of technology Thonburi).

[15] Fukui, T., Shiraishi, T., Murakami, T., and Nakajima, N. (1999). Study on high specific power microStirling engine. JSME International Journal Series B Fluids and Thermal Engineering, 42(4), 776-782.

[16] Iwamoto, S., Toda, F., Hirata, K., Takeuchi, M., and Yamamoto, T. (1997, May). Comparison of low-and high-temperature differential Stirling engines. In Proceedings of eighth International Stirling engine conference (pp. 29-38).

[17] Wu, F., Chen, L., Wu, C., and Sun, F. (1998). Optimum performance of irreversible Stirling engine with imperfect regeneration. Energy Conversion and Management, 39(8), 727-732.

[18] Erbay, L. B., and Yavuz, H. (1997). Analysis of the Stirling heat engine at maximum power conditions. Energy, 22(7), 645-650.

[19] Ahmadi, M. H., and Hosseinzade, H. (2012). Investigation of solar collector design parameters effect onto solar stirling engine efficiency. J Applied Mechanic Engg, 1(102), 2.

[20] Ahmadi, M. H., Aghaj, S. S. G., and Nazeri, A. (2013). Prediction of power in solar stirling heat engine by using neural network based on hybrid genetic algorithm and particle swarm optimization. Neural Computing and Applications, 22(6), 1141-1150.

[21] Ahmadi, M. H., Ahmadi, M. A., Sadatsakkak, S. A., and Feidt, M. (2015). Connectionist intelligent model estimates output power and torque of stirling engine. Renewable and Sustainable Energy Reviews, 50, 871-883. [22] Ahmadi, M., Ahmadi, M. A., Mehrpooya, M., and Rosen, M. (2015). Using GMDH neural networks to model the power and torque of a stirling engine. Sustainability, 7(2), 2243-2255.

[23] Toghyani, S., Ahmadi, M. H., Kasaeian, A., and Mohammadi, A. H. (2016). Artificial neural network, ANNPSO and ANN-ICA for modelling the Stirling engine. International Journal of Ambient Energy, 37(5), 456-468.

[24] Curzon, F. L., and Ahlborn, B. (1975). Efficiency of a Carnot engine at maximum power output. American Journal of Physics, 43(1), 22-24.

[25] Novikov, I. I. (1958). The efficiency of atomic power stations (a review). Journal of Nuclear Energy (1954), 7(1-2), 125-128.

[26] Wu, C. (1988). Power optimization of a finite-time Carnot heat engine. Energy, 13(9), 681-687.

[27] Yan, Z., and Chen, L. (1995). The fundamental optimal relation and the bounds of power output and efficiency for an irreversible Carnot engine. Journal of Physics A: Mathematical and General, 28(21), 6167.

[28] Chen, J. (1994). The maximum power output and maximum efficiency of an irreversible Carnot heat engine. Journal of Physics D: Applied Physics, 27(6), 1144.

[29] Angulo-Brown, F. (1991). An ecological optimization criterion for finite-time heat engines. Journal of Applied Physics, 69(11), 7465-7469.

[30] Chen, L., Xiaoqin, Z., Sun, F., and Wu, C. (2004). Ecological optimization for generalized irreversible Carnot refrigerators. Journal of Physics D: Applied Physics, 38(1), 113.

[31] Chen, L., Zhang, W., and Sun, F. (2007). Power, efficiency, entropy-generation rate and ecological optimization for a class of generalized irreversible universal heat-engine cycles. Applied Energy, 84(5), 512-525.

[32] Chen, L., Zhou, J., Sun, F., and Wu, C. (2004). Ecological optimization for generalized irreversible Carnot engines. Applied Energy, 77(3), 327-338.

[33] Chen, L., Xiaoqin, Z., Sun, F., and Wu, C. (2007). Exergy-based ecological optimization for a generalized irreversible Carnot heat-pump. Applied Energy, 84(1), 78-88.

[34] Ge, Y., Chen, L., and Sun, F. (2016). Progress in finite time thermodynamic studies for internal combustion engine cycles. Entropy, 18(4), 139.

[35] Chen, L., Meng, F., and Sun, F. (2016). Thermodynamic analyses and optimization for thermoelectric devices: The state of the arts. Science China Technological Sciences, 59(3), 442-455.

[36] Cheng, C. Y. (1997). The ecological optimization of an irreversible Carnot heat engine. Journal of physics D: Applied physics, 30(11), 1602.

[37] Xia, D., Chen, L., Sun, F., and Wu, C. (2006). Universal ecological performance for endo-reversible heat engine cycles. International journal of ambient energy, 27(1), 15-20.

[38] Zhang, W., Chen, L., Sun, F., and Wu, C. (2007). Exergy-based ecological optimal performance for a universal endoreversible thermodynamic cycle. International Journal of Ambient Energy, 28(1), 51-56.

[39] Chen, L., Zhu, X., Sun, F., and Wu, C. (2006). Exergy-based ecological optimization of linear phenomenological heat-transfer law irreversible Carnot-engines. Applied Energy, 83(6), 573-582.

[40] Zhu, X., Chen, L., Sun, F., and Wu, C. (2003). The ecological optimisation of a generalised irreversible Carnot engine for a generalised heat transfer law. International journal of ambient energy, 24(4), 189-194.

[41] Zhu, X., Chen, L., Sun, F., and Wu, C. (2005). Effect of heat transfer law on the ecological optimization of a generalized irreversible Carnot engine. Open Systems and Information Dynamics, 12(03), 249-260.

[42] Li, J., Chen, L., and Sun, F. (2011). Ecological performance of an endoreversible Carnot heat engine with complex heat transfer law. International Journal of Sustainable Energy, 30(1), 55-64. 
[43] Li, J., Chen, L., and Sun, F. (2011). Ecological performance of a generalized irreversible Carnot heat engine with complex heat transfer law. Int. J. Energy and Environment, 2(1), 57-70.

[44] Tu, Y., Chen, L., Sun, F., and Wu, C. (2006). Exergy-based ecological optimisation for an endoreversible Brayton refrigeration cycle. International Journal of Exergy, 3(2), 191-201.

[45] Chen, L., Xiaoqin, Z., Sun, F., and Wu, C. (2004). Ecological optimization for generalized irreversible Carnot refrigerators. Journal of Physics D: Applied Physics, 38(1), 113.

[46] Chen, L., Xiaoqin, Z., Sun, F., and Wu, C. (2007). Exergy-based ecological optimization for a generalized irreversible Carnot heat-pump. Applied Energy, 84(1), 78-88.

[47] Chen, L., Xiaoqin, Z., Sun, F., and Wu, C. (2007). Exergy-based ecological optimization for a generalized irreversible Carnot heat-pump. Applied Energy, 84(1), 78-88.

[48] Chen, L., Xiaoqin, Z., Sun, F., and Wu, C. (2007). Ecological optimisation of a generalised irreversible Carnot refrigerator for a generalised heat transfer law. International Journal of Ambient Energy, 28(4), 213-219.

[49] Li, J., Chen, L., Sun, F., and Wu, C. (2011). Ecological performance of an endoreversible Carnot refrigerator with complex heat transfer law. International Journal of Ambient Energy, 32(1), 31-36.

[50] Chen, L., Li, J., and Sun, F. (2012). Ecological optimization of a generalized irreversible Carnot refrigerator in the case of $\mathrm{Q} \propto(\Delta \mathrm{T} n) \mathrm{m}$. International Journal of Sustainable Energy, 31(1), 59-72.

[51] Tyagi, S. K., Kaushik, S. C., and Salohtra, R. (2002). Ecological optimization and parametric study of irreversible Stirling and Ericsson heat pumps. Journal of Physics D: Applied Physics, 35(16), 2058.

[52] Zhu, X., Chen, L., Sun, F., and Wu, C. (2005). Effect of heat transfer law on the ecological optimization of a generalized irreversible Carnot engine. Open Systems and Information Dynamics, 12(03), 249-260.

[53] Zhu, X., Chen, L., Sun, F., and Wu, C. (2005). The ecological optimization of a generalized irreversible Carnot heat pump for a generalized heat transfer law. Journal of the Energy Institute, 78(1), 5-10.

[54] Chen L, Li J, Sun F, and Wu C (2009). Effect of a complex generalized heat transfer law on ecological performance of an endoreversible Carnot heat pump. Int J Ambient Energy, 30, 102-8.

[55] Zhu, X., Chen, L., Sun, F., and Wu, C. (2001). Optimum performance of a generalized irreversible Carnot heat pump with a generalized heat transfer law. Physica Scripta, 64(6), 584.

[56] Liu, X., Chen, L., Wu, F., and Sun, F. (2009). Ecological optimization of an irreversible harmonic oscillators Carnot heat engine. Science in China Series G: Physics, Mechanics and Astronomy, 52(12), 1976-1988.

[57] Wang, W. H., Chen, L. G., Sun, F. R., and Wu, C. (2006). Optimal heat conductance distribution and optimal intercooling pressure ratio for power optimisation of irreversible closed intercooled regenerated Brayton cycle. Journal of the Energy Institute, 79(2), 116-119.

[58] Wang, W., Chen, L., and Sun, F. (2011). Ecological optimisation of an irreversible-closed ICR gas turbine cycle. International Journal of Exergy, 9(1), 66-79.

[59] Tyagi, S. K., Kaushik, S. C., and Salhotra, R. (2002). Ecological optimization and performance study of irreversible Stirling and Ericsson heat engines. Journal of Physics D: Applied Physics, 35(20), 2668.

[60] Zhu, X., Chen, L., Sun, F., and Wu, C. (2006). Exergy-based ecological optimization for a generalized irreversible Carnot refrigerator. Journal of the Energy Institute, 79(1), 42-46.

[61] Wu C, Chen L, and Sun F (2006). Ecological optimization performance of an irreversible quantum SI engine powering with an ideal Fermi gas. Open Sys Inform Dynam, 13, 55-66.

[62] Acikkalp, E. (2013). Models for optimum thermo-ecological criteria of actual thermal cycles. Thermal Science, 17(3).

[63] Ust, Y., Sahin, B., and Sogut, O. S. (2005). Performance analysis and optimization of an irreversible dualcycle based on an ecological coefficient of performance criterion. Applied energy, 82(1), 23-39.

[64] Ust, Y., and Sahin, B. (2007). Performance optimization of irreversible refrigerators based on a new thermoecological criterion. International Journal of Refrigeration, 30(3), 527-534.

[65] Ust, Y., Sahin, B., Kodal, A., and Akcay, I. H. (2006). Ecological coefficient of performance analysis and optimization of an irreversible regenerative-Brayton heat engine. Applied Energy, 83(6), 558-572.

[66] Sogut, O. S., Ust, Y., and Sahin, B. (2006). The effects of intercooling and regeneration on the thermoecological performance analysis of an irreversible-closed Brayton heat engine with variable-temperature thermal reservoirs. Journal of Physics D: Applied Physics, 39(21), 4713.

[67] Ust, Y. (2010). Effect of regeneration on the thermo-ecological performance analysis and optimization of irreversible air refrigerators. Heat and mass transfer, 46(4), 469-478.

[68] Ust, Y. (2009). Performance analysis and optimization of irreversible air refrigeration cycles based on ecological coefficient of performance criterion. Applied Thermal Engineering, 29(1), 47-55.

[69] Ust, Y., Sogut, O. S., Sahin, B., and Durmayaz, A. (2006). Ecological coefficient of performance (ECOP) optimization for an irreversible Brayton heat engine with variable-temperature thermal reservoirs. Journal of the Energy Institute, 79(1), 47-52.

[70] Ust, Y., Sahin, B., and Kodal, A. (2006). Performance analysis of an irreversible Brayton heat engine based on ecological coefficient of performance criterion. International Journal of Thermal Sciences, 45(1), 94-101. 
[71] Üst, Y., Sahin, B., and Kodal, A. (2005). Ecological coefficient of performance (ECOP) optimization for generalized irreversible Carnot heat engines. Journal of the Energy Institute, 78(3), 145-151.

[72] Ust, Y., Safa, A., and Sahin, B. (2005). Ecological performance analysis of an endoreversible regenerative Brayton heat-engine. Applied Energy, 80(3), 247-260.

[73] Ust, Y., Akkaya, A. V., and Safa, A. (2011). Analysis of a vapour compression refrigeration system via exergetic performance coefficient criterion. Journal of the Energy Institute, 84(2), 66-72.

[74] Akkaya, A. V., Sahin, B., and Erdem, H. H. (2008). An analysis of SOFC/GT CHP system based on exergetic performance criteria. International Journal of Hydrogen Energy, 33(10), 2566-2577.

[75] Akkaya, A. V., Sahin, B., and Erdem, H. H. (2007). Exergetic performance coefficient analysis of a simple fuel cell system. International Journal of Hydrogen Energy, 32(17), 4600-4609.

[76] Ust, Y., Sahin, B., and Kodal, A. (2007). Optimization of a dual cycle cogeneration system based on a new exergetic performance criterion. Applied Energy, 84(11), 1079-1091.

[77] Ust, Y., Sahin, B., and Yilmaz, T. (2007). Optimization of a regenerative gas-turbine cogeneration system based on a new exergetic performance criterion: exergetic performance coefficient. Proceedings of the Institution of Mechanical Engineers, Part A: Journal of Power and Energy, 221(4), 447-456.

[78] Gonca, G. (2017). Application of a novel thermo-ecological performance criterion: effective ecological power density (EFECPOD) to a Joule-Brayton cycle (JBC) turbine. Journal of Thermal Engineering, 3(5), 14781488 .

[79] Mironova, V. A., Tsirlin, A. M., Kazakov, V. A., and Berry, R. S. (1994). Finite-time thermodynamics: Exergy and optimization of time-constrained processes. Journal of applied physics, 76(2), 629-636.

[80] Sieniutycz, S., and von Spakovsky, M. R. (1998). Finite time generalization of thermal exergy. Energy conversion and management, 39(14), 1423-1447.

[81] Sieniutycz, S. (1998). Generalized Carnot problem of maximum work in finite time via Hamilton-JacobiBellman theory. Energy conversion and management, 39(16-18), 1735-1743.

[82] Sieniutycz, S. (1999). Carnot problem of maximum work from a finite resource interacting with environment in a finite time. Physica A: Statistical Mechanics and its Applications, 264(1-2), 234-263.

[83] Sieniutycz, S. (1997). Hamilton-Jacobi-Bellman theory of dissipative thermal availability. Physical Review E, 56(5), 5051.

[84] Li, J., Chen, L., and Sun, F. (2009). Optimum work in real systems with a class of finite thermal capacity reservoirs. Mathematical and Computer Modelling, 49(3-4), 542-547.

[85] Li, J., Chen, L., and Sun, F. (2010). Maximum work output of multistage continuous Carnot heat engine system with finite reservoirs of thermal capacity and radiation between heat source and working fluid. Thermal Sci, 14(1), 1-9.

[86] Li, J., Chen, L. G., and Sun, F. R. (2009). Extremal work of an endoreversible system with two finite thermal capacity reservoirs.

[87] Xia, S. J., Chen, L. G., and Sun, F. R. (2010). Effects of mass transfer laws on finite time exergy. Journal of the Energy Institute, 83(4), 210-216.

[88] Xia, S., Chen, L., and Sun, F. (2011). Power-optimization of non-ideal energy converters under generalized convective heat transfer law via Hamilton-Jacobi-Bellman theory. Energy, 36(1), 633-646.

[89] Xia, S. J., Chen, L. G., and Sun, F. R. (2012). Finite time exergy with generalised heat transfer law. Journal of the Energy Institute, 85(2), 70-77.

[90] Sharma, A., Shukla, S. K., and Rai, A. K. (2011). Finite time thermodynamic analysis and optimization of solar-dish stirling heat engine with regenerative losses. Thermal Science, 15(4).

[91] Yaqi, L., Yaling, H., and Weiwei, W. (2011). Optimization of solar-powered Stirling heat engine with finitetime thermodynamics. Renewable energy, 36(1), 421-427.

[92] Ahmadi, M. H., Sayyaadi, H., and Hosseinzadeh, H. (2015). Optimization of Output Power and Thermal Efficiency of Solar-Dish Stirling Engine Using Finite Time Thermodynamic Analysis. Heat Transfer-Asian Research, 44(4), 347-376.

[93] Tlili, I. (2012). Finite time thermodynamic evaluation of endoreversible Stirling heat engine at maximum power conditions. Renewable and Sustainable Energy Reviews, 16(4), 2234-2241.

[94] Kaushik, S. C., and Kumar, S. (2001). Finite time thermodynamic evaluation of irreversible Ericsson and Stirling heat engines. Energy Conversion and Management, 42(3), 295-312.

[95] Kaushik, S. C., and Kumar, S. (2000). Finite time thermodynamic analysis of endoreversible Stirling heat engine with regenerative losses. Energy, 25(10), 989-1003.

[96] Kaushik, S. C., Tyagi, S. K., and Mohan, S. (2003). Performance evaluation of an irreversible Stirling heat engine cycle. International journal of ambient energy, 24(3), 149-156.

[97] Tyagi, S. K., Chen, J., Lin, G., and Kaushik, S. C. (2004). Thermoeconomic optimization and parametric study of an irreversible Ericsson heat engine cycle. Int. J. Appl. Thermodynamics, 7(4), 189-198.

[98] Veldhuizen, D.A.V., Lamont, G.B. (2000). Multiobjective evolutionary algorithms: analyzing the state-ofthe-art, Evolutionary computation, 8, 125-147 
[99] Konak, A., Coit, D. W., and Smith, A. E. (2006). Multi-objective optimization using genetic algorithms: A tutorial. Reliability Engineering and System Safety, 91(9), 992-1007.

[100] Bäck, T., Fogel, D. B., and Michalewicz, Z. (1997). Handbook of evolutionary computation. CRC Press.

[101] Ahmadi, M. H., Hosseinzade, H., Sayyaadi, H., Mohammadi, A. H., and Kimiaghalam, F. (2013). Application of the multi-objective optimization method for designing a powered Stirling heat engine: design with maximized power, thermal efficiency and minimized pressure loss. Renewable Energy, 60, 313-322.

[102] Zhang, J., Zhu, H., Yang, C., Li, Y., and Wei, H. (2011). Multi-objective shape optimization of helico-axial multiphase pump impeller based on NSGA-II and ANN. Energy Conversion and Management, 52(1), 538-546. [103] Ahmadi, M. H., Sayyaadi, H., Dehghani, S., and Hosseinzade, H. (2013). Designing a solar powered Stirling heat engine based on multiple criteria: maximized thermal efficiency and power. Energy Conversion and Management, 75, 282-291.

[104] Lazzaretto, A., and Toffolo, A. (2004). Energy, economy and environment as objectives in multi-criterion optimization of thermal systems design. Energy, 29(8), 1139-1157.

[105] Ahmadi, M. H., Sayyaadi, H., Mohammadi, A. H., and Barranco-Jimenez, M. A. (2013). Thermoeconomic multi-objective optimization of solar dish-Stirling engine by implementing evolutionary algorithm. Energy Conversion and Management, 73, 370-380.

[106] Ahmadi, M. H., Ahmadi, M. A., Maleki, A., Pourfayaz, F., Bidi, M., and Açıkkalp, E. (2017). Exergetic sustainability evaluation and multi-objective optimization of performance of an irreversible nanoscale Stirling refrigeration cycle operating with Maxwell-Boltzmann gas. Renewable and Sustainable Energy Reviews, 78, 8092.

[107] Atashkari, K., Nariman-Zadeh, N., Gölcü, M., Khalkhali, A., and Jamali, A. J. E. C. (2007). Modelling and multi-objective optimization of a variable valve-timing spark-ignition engine using polynomial neural networks and evolutionary algorithms. Energy Conversion and Management, 48(3), 1029-1041.

[108] Ahmadi, M. H., Ahmadi, M. A., Bayat, R., Ashouri, M., and Feidt, M. (2015). Thermo-economic optimization of Stirling heat pump by using non-dominated sorting genetic algorithm. Energy Conversion and Management, 91, 315-322.

[109] Ahmadi, M. H., Ahmadi, M. A., Mellit, A., Pourfayaz, F., and Feidt, M. (2016). Thermodynamic analysis and multi objective optimization of performance of solar dish Stirling engine by the centrality of entransy and entropy generation. International Journal of Electrical Power and Energy Systems, 78, 88-95.

[110] Toghyani, S., Kasaeian, A., and Ahmadi, M. H. (2014). Multi-objective optimization of Stirling engine using non-ideal adiabatic method. Energy Conversion and Management, 80, 54-62.

[111] Ahmadi, M. H., Ahmadi, M. A., Pourfayaz, F., and Bidi, M. (2016). Thermodynamic analysis and optimization for an irreversible heat pump working on reversed Brayton cycle. Energy conversion and management, 110, 260-267.

[112] Ahmadi, M. H., Ahmadi, M. A., Mehrpooya, M., Feidt, M., and Rosen, M. A. (2016). Optimal design of an Otto cycle based on thermal criteria. Mechanics and Industry, 17(1), 111.

[113] Ahmadi, M. H., Ahmadi, M. A., Mohammadi, A. H., Feidt, M., and Pourkiaei, S. M. (2014). Multiobjective optimization of an irreversible Stirling cryogenic refrigerator cycle. Energy Conversion and Management, 82, 351-360.

[114] Ahmadi, M. H., Ahmadi, M. A., Mohammadi, A. H., Mehrpooya, M., and Feidt, M. (2014). Thermodynamic optimization of Stirling heat pump based on multiple criteria. Energy Conversion and Management, 80, 319-328.

[115] Ahmadi, M. H., Mohammadi, A. H., Dehghani, S., and Barranco-Jimenez, M. A. (2013). Multi-objective thermodynamic-based optimization of output power of Solar Dish-Stirling engine by implementing an evolutionary algorithm. Energy conversion and Management, 75, 438-445.

[116] Ahmadi, M. H., Mohammadi, A. H., and Pourkiaei, S. M. (2016). Optimisation of the thermodynamic performance of the Stirling engine. International Journal of Ambient Energy, 37(2), 149-161.

[117] Sayyaadi, H., Ahmadi, M. H., and Dehghani, S. (2014). Optimal design of a solar-driven heat engine based on thermal and ecological criteria. Journal of Energy Engineering, 141(3), 04014012.

[118] Sahraie, H., Mirani, M. R., Ahmadi, M. H., and Ashouri, M. (2015). Thermo-economic and thermodynamic analysis and optimization of a two-stage irreversible heat pump. Energy conversion and management, 99, 81-91.

[119] Ahmadi, M. H., Ahmadi, M. A., Mehrpooya, M., Hosseinzade, H., and Feidt, M. (2014). Thermodynamic and thermo-economic analysis and optimization of performance of irreversible four-temperature-level absorption refrigeration. Energy conversion and management, 88, 1051-1059.

[120] Ahmadi, M. H., and Ahmadi, M. A. (2015). Thermodynamic analysis and optimization of an irreversible Ericsson cryogenic refrigerator cycle. Energy Conversion and Management, 89, 147-155.

[121] Ahmadi, M. H., Ahmadi, M. A., Mehrpooya, M., and Sameti, M. (2015). Thermo-ecological analysis and optimization performance of an irreversible three-heat-source absorption heat pump. Energy Conversion and Management, 90, 175-183. 
[122] Ahmadi, M. H., Ahmadi, M. A., and Feidt, M. (2016). Performance optimization of a solar-driven multistep irreversible brayton cycle based on a multi-objective genetic algorithm. Oil and Gas Science and Technology-Revue d'IFP Energies nouvelles, 71(1), 16.

[123] Ahmadi, M. H., Ahmadi, M. A., and Feidt, M. (2015). Thermodynamic analysis and evolutionary algorithm based on multi-objective optimization of performance for irreversible four-temperature-level refrigeration. Mechanics and Industry, 16(2), 207.

[124] Sadatsakkak, S. A., Ahmadi, M. H., and Ahmadi, M. A. (2015). Thermodynamic and thermo-economic analysis and optimization of an irreversible regenerative closed Brayton cycle. Energy conversion and management, 94, 124-129.

[125] Sadatsakkak, S. A., Ahmadi, M. H., Bayat, R., Pourkiaei, S. M., and Feidt, M. (2015). Optimization density power and thermal efficiency of an endoreversible Braysson cycle by using non-dominated sorting genetic algorithm. Energy Conversion and Management, 93, 31-39.

[126] Ahmadi, M. H., Ahmadi, M. A., and Sadatsakkak, S. A. (2015). Thermodynamic analysis and performance optimization of irreversible Carnot refrigerator by using multi-objective evolutionary algorithms (MOEAs). Renewable and Sustainable Energy Reviews, 51, 1055-1070.

[127] Ahmadi, M. H., and Mehrpooya, M. (2015). Thermo-economic modeling and optimization of an irreversible solar-driven heat engine. Energy conversion and management, 103, 616-622.

[128] Ahmadi, M. H., Ahmadi, M. A., and Pourfayaz, F. (2015). Performance assessment and optimization of an irreversible nano-scale Stirling engine cycle operating with Maxwell-Boltzmann gas. The European Physical Journal Plus, 130(9), 190.

[129] Ahmadi, M. H., Ahmadi, M. A., Shafaei, A., Ashouri, M., and Toghyani, S. (2016). Thermodynamic analysis and optimization of the Atkinson engine by using NSGA-II. International Journal of Low-Carbon Technologies, 11(3), 317-324.

[130] Ahmadi, M. H., Dehghani, S., Mohammadi, A. H., Feidt, M., and Barranco-Jimenez, M. A. (2013). Optimal design of a solar driven heat engine based on thermal and thermo-economic criteria. Energy Conversion and Management, 75, 635-642.

[131] Ahmadi, M. H., Ahmadi, M. A., and Pourfayaz, F. (2016). Thermodynamic analysis and evolutionary algorithm based on multi-objective optimization performance of actual power generating thermal cycles. Applied Thermal Engineering, 99, 996-1005.

[132] Ahmadi, M. H., and Ahmadi, M. A. (2016). Multi objective optimization of performance of three-heatsource irreversible refrigerators based algorithm NSGAII. Renewable and Sustainable Energy Reviews, 60, 784794.

[133] Hussein, A. K. (2015). Multi-objective optimization of a three-dimensional internally finned tube based on Response Surface Methodology (RSM). Journal of Thermal Engineering, 1(2), 131-142.

[134] Ahmadi, M. H., Nabakhteh, M. A., Ahmadi, M. A., Pourfayaz, F., and Bidi, M. (2017). Investigation and optimization of performance of nano-scale Stirling refrigerator using working fluid as Maxwell-Boltzmann gases. Physica A: Statistical Mechanics and its Applications, 483, 337-350.

[135] Wong, J. Y., Sharma, S., and Rangaiah, G. P. (2016). Design of shell-and-tube heat exchangers for multiple objectives using elitist non-dominated sorting genetic algorithm with termination criteria. Applied Thermal Engineering, 93, 888-899.

[136] Rahdar, M. H., Heidari, M., Ataei, A., and Choi, J. K. (2016). Modeling and optimization of R-717 and R134a ice thermal energy storage air conditioning systems using NSGA-II and MOPSO algorithms. Applied Thermal Engineering, 96, 217-227.

[137] Aminyavari, M., Najafi, B., Shirazi, A., and Rinaldi, F. (2014). Exergetic, economic and environmental (3E) analyses, and multi-objective optimization of a $\mathrm{CO} 2 / \mathrm{NH} 3$ cascade refrigeration system. Applied Thermal Engineering, 65(1-2), 42-50.

[138] Mamaghani, A. H., Najafi, B., Shirazi, A., and Rinaldi, F. (2015). Exergetic, economic, and environmental evaluations and multi-objective optimization of a combined molten carbonate fuel cell-gas turbine system. Applied Thermal Engineering, 77, 1-11.

[139] Ahmadi, M. H., Jokar, M. A., Ming, T., Feidt, M., Pourfayaz, F., and Astaraei, F. R. (2018). Multi-objective performance optimization of irreversible molten carbonate fuel cell-Braysson heat engine and thermodynamic analysis with ecological objective approach. Energy, 144, 707-722.

[140] Ahmadi, M. H., Ahmadi, M. A., Açıkkalp, E., Alhuyi Nazari, M., Arab Pour Yazdi, M., and Kumar, R. (2018). New thermodynamic analysis and optimization of performance of an irreversible diesel cycle. Environmental Progress and Sustainable Energy, 37(4), 1475-1490.

[141] Mazur, V. (2007). Fuzzy thermoeconomic optimization of energy-transforming systems. Applied Energy, 84(7-8), 749-762.

[142] Olson, D. L. (1996). Decision aids for selection problems. Springer Science and Business Media. 